\title{
As redes sociais dos empreendedores na formação do capital social: um estudo de casos múltiplos em municípios do norte pioneiro no estado do Paraná
}

\author{
Entrepreneurs' social networks in the formation of social capital: a multiple case study in \\ towns located in the pioneer north region of the Paraná state
}

\author{
Norma Pimenta Cirilo Ducci ${ }^{1}$ \\ Rivanda Meira Teixeira ${ }^{2}$
}

\section{Resumo}

Quando as redes sociais, construídas pelos contatos formais e informais, contribuem para o alcance dos objetivos dos empreendedores, essas redes são seu capital social (BURT, 1992). Este trabalho tem como objetivo compreender como as redes sociais são utilizadas pelos empreendedores na construção do seu capital social. Especificamente, analisam-se quais os tipos de redes desenvolvidos pelos empreendedores e quais os recursos acessados através desses relacionamentos na criação e desenvolvimento do negócio. Realizou-se um estudo qualitativo de casos múltiplos em três empreendimentos localizados na região norte pioneiro do Paraná. As evidências foram coletadas por meio de entrevistas semiestruturadas com os empreendedores, observação e análise de documentos. Os resultados do trabalho sugerem que nas duas fases dos negócios, de criação e desenvolvimento, a rede social dos empreendedores permitiram acesso aos diferentes recursos que influenciaram de forma significativa na trajetória e nos resultados alcançados. Ainda, partindo da ideia de que capital social é o benefício que pode ser derivado da rede social, é procedente afirmar que os diferentes recursos acessados pelos empreendedores do estudo contribuíram para a formação do seu capital social.

Palavras chave: Redes sociais. Redes sociais empreendedoras. Capital social. Empreendedorismo.

\begin{abstract}
When social networks built by formal and informal contacts contribute to the accomplishment of entrepreneurs' objectives, these networks are their social capital (BURT,1992). This study aims to understand how social networks are used by entrepreneurs in the construction of their social capital. Specifically, it analyzes what types of networks are developed by entrepreneurs and what resources are accessed by them in the businesses creation and development stages. A qualitative study of multiples cases was carried out in the north of Paraná state. Evidence was collected through semi-structured interviews with the entrepreneurs, observation and documents analysis. The results of this study suggest that in the creation and development phases, an entrepreneur's social networks grants access to different resources that meaningfully influence business results. Yet, from the idea that social capital is beneficial and can be derived from social networks, it is possible to state that the different resources accessed by the entrepreneurs contribute to the formation of their social capital.
\end{abstract}

Keywords: Social networks. Entrepreneus social networks. Social capital. Entrepreneurship.

Artigo submetido em 11 de abril de 2009 e aceito para publicação em 04 de maio de 2011.

1 Mestre em Administração pela Universidade Federal do Paraná. Endereço: Av. Prefeito Lothario Meisser, 3400, Jardim Botânico, CEP 80210-179, Curitiba, PR. E-mail: norma@onda.com.br

2 Doutora em Administração pela Cranfield University, Inglaterra; Professora do Mestrado em Administração da Universidade Federal de Sergipe. Endereço: Mestrado em Administração, Campus Universitário, São Cristóvão, Sergipe, CEP 49000-000. E-mail: rivandateixeira@terra.com.br. 


\section{Introdução}

Segundo Aldrich e Elam (1997), novos negócios são criados como resultado da motivação que os empreendedores ganham, quando tiveram acesso a recursos, e descobriram novas oportunidades de negócios. Assim, desde o início de um negócio, a rede social destaca-se como fator muito importante para os donos de negócios. Mas o desenvolvimento de relações não é importante somente para fundar um negócio ou para o sucesso do negócio, elas também impactam no contínuo desenvolvimento da empresa.

Se a rede social dos empreendedores contribui para o atingimento dos objetivos empresariais, ou seja, quando as redes sociais, construídas pelos contatos formais e informais, contribuem para o alcance dos objetivos dos empreendedores, essas redes são seu capital social (BURT, 1992; PUTNAM, 1995). Lin (2001b) declara que a noção de capital social como investimento em relações sociais espera retorno; capital social é dessa forma visto como o benefício que pode derivar de redes sociais. $\mathrm{O}$ autor ainda considera o capital social como um conjunto de recursos tangíveis ou virtuais que advêm para os atores através da estrutura social, facilitando a realização dos objetivos destes.

Para Hansen (1995), estrutura social é o relacionamento entre os empreendedores e os membros de sua rede de relacionamentos. Essa estrutura existente no ambiente empreendedor pode trazer recursos sociais para os negócios, especialmente para novos negócios que estão se estabelecendo. Dentro desses recursos eles incluem os contatos, que ajudam esses atores a conseguir que as coisas sejam feitas. Os contatos são as pessoas que os empreendedores conhecem ou pessoas que seus conhecidos conhecem. Assim, explorar os tipos de redes sociais que são mobilizadas pelos empreendedores das empresas no decorrer da criação e do desenvolvimento de novos negócios e identificar os recursos acessados por meio dos relacionamentos são elementos considerados importantes para os empreendedores (BORGES, 2007).

Birley (1985) destaca que o empreendedor não depende apenas de recursos físicos e financeiros para iniciar um novo negócio ou para o seu crescimento, mas também de conselhos, informações, opiniões, confiança e contatos de negócios. Para a autora, o capital social que existe nas relações entre pessoas, ou seja, na rede social do empreendedor, pode ser considerado capital, uma vez que contribui para abrir caminhos no momento em que oferece e multiplica as possibilidades advindas das informações e dos conhecimentos das pessoas que fazem parte dessa rede, minimizando riscos e maximizando oportunidades.

Tem como objetivo geral analisar como as redes sociais são utilizadas pelos empreendedores na formação do capital social, nas fases de criação e de desenvolvimento de novos negócios em municípios na região norte pioneiro do Paraná. Especificamente pretende identificar os tipos de redes sociais que são utilizadas pelos empreendedores na formação do seu capital social, e analisar como essas redes sociais influenciam na obtenção de recursos financeiros, físicos e sociais nessas fases do negócio.

O presente estudo pretende contribuir teoricamente, através da utilização dos conceitos de rede social e de capital social, em um contexto de empresas localizadas na região norte pioneiro do Paraná. Pretende ainda auxiliar os empreendedores na compreensão do desenvolvimento de sua rede social na formação do capital social, que poderão auxiliar no alcance das suas metas ou no seu sucesso.

\section{Redes Sociais}

A vida em sociedade provoca naturalmente a aproximação entre os indivíduos, que estabelecem ligações (também chamadas de nós ou laços) mais ou menos densas, mais ou menos consistentes quanto à sua duração, ao número de pessoas envolvidas e à atividade que desenvolvem. (PROULX, 1995, apud RIBEIRO e SANTOS, 2003). Hoje se considera que o mundo é uma "sociedade em rede" (CASTELLS, 1999). Uma 
rede (network) é "geralmente definida como um tipo específico de relação que liga um conjunto de pessoas, objetos ou eventos" (KNOKE e KUKLINSKI, 1996, p. 175, tradução nossa).

Graficamente, uma rede é semelhante a uma teia, um conjunto de nós interconectados (CASTELLS, 1999), os nós são representados pelos pontos de intersecção das linhas. Se o ponto ou o nó de uma rede for um ator social, tem-se uma rede social (Social Network). Esta é uma delimitação conceitual mais ligada à área da sociologia, mas tem sido utilizada em diversos campos e níveis como o individual, grupal, organizacional e societária (LOPES, 2004); este conceito favorece análises, pois redes sociais são, empiricamente, formadas por relacionamentos entre atores, tanto individuais quanto coletivos. $\mathrm{O}$ termo rede se refere a um conjunto de objetos, ou nós, e um mapeamento ou descrição do relacionamento entre os objetos. No caso de redes sociais, os objetos referem-se às pessoas ou grupos de pessoas (ALDRICH e ZIMMER, 1986).

Redes podem ser visualizadas como uma série de relacionamentos dinâmicos estabelecidos pela troca de ideias, informações, mercadorias, poder e amizade (TICHY et al., 1979, apud ALDRICH e ZIMMER, 1986). Por sua vez, as redes sociais proveem fontes para aquisição de escassos meios, tais como, capital e informação (PORTES, 1995, apud LI, 2004) ou apoio para a ideia de que a rede de indivíduos pode tirar proveito de oportunidades em áreas nas quais eles não tenham nenhum especialista direto (ALDRICH e ZIMMER, 1986; OSTGAARD e BIRLEY, 1996).

A teoria de rede social é um ramo da ciência social que se aplica a uma ampla variedade de organizações humanas, desde grupos pequenos de pessoas, até nações inteiras. Ela sugere que a ação econômica envolvida nas redes sociais e a configuração destas podem ter um impacto nos resultados econômicos (LI, 2004).

Para Lopes (2004), as redes são mais do que um conjunto de relacionamentos sociais que se reproduzem e apresentam padrões persistentes ao longo do tempo. Elas envolvem um conjunto de dois elementos: atores (pessoas, instituições ou grupos) e suas conexões (WASSERMAN e FAUST, 1994). A conexão apresentada entre dois atores em uma rede social é denominada laço social, de acordo com Wasserman e Faust (1994), ou seja, aquilo que estabelece a ligação entre os pares de atores. Um laço é composto por relações sociais que, por sua vez, são constituídas por interações sociais.

A preocupação com o assunto rede social e sua relação com os empreendedores tem-se destacado em pesquisas e essa interação tem sido reconhecida como determinante do processo empreendedor, como também do sucesso dos empreendimentos. (ALDRICH, ROSEN e WOODWARD, 1987; GREVE e SALAFF, 2003).

Quando os empreendedores usam as redes sociais para suportar as atividades de negócios temos as redes sociais empreendedoras.

\section{Redes Sociais Empreendedoras}

Pela história do empreendedorismo, nota-se que a pesquisa na área de empreendedorismo mudou seu foco das características psicológicas e comportamentos individuais dos empreendedores para um entendimento mais geral sobre a dinâmica social do empreendedorismo (LI, 2004).

A imagem popular do empreendedor como figura isolada que supera obstáculos e afasta os perigos sozinho não existe. No domínio econômico é comum desencadearem-se relações de amizade e de confiança mútua entre empreendedores ou indivíduos (OSTGAARD e BIRLEY, 1994) quando desenvolvem a sua atividade econômica em determinado setor, numa região, ou num país. Em conversas ou contatos informais, empreendedores trocam informações sobre oportunidades de negócios, solicitam opiniões sobre tendências do mercado e pronunciam-se sobre a realidade econômica e social do país ou região onde intervêm. Em 
algumas das decisões empresariais tomadas, é mesmo visível a influência exercida pelo seu grupo de pares ou pela sua rede social.

Aldrich e Dubini (1991) definem que a rede de relacionamentos (networking) é uma poderosa ferramenta para os empreendedores que desejam expandir seu campo de ação e economizar tempo. É fenômeno que se espalha por todo o mundo. Para Timmons (1994, apud LI, 2004), as redes são vistas como um mecanismo para influenciar recursos dos seus donos, isto é, ganhar acesso aos recursos de outras pessoas, procurando uma oportunidade para ganhar empréstimos empreendedores.

A literatura sobre rede empreendedora aponta que as redes sociais empreendedoras são relacionadas de forma positiva com o desempenho da organização ou, para ser mais específico, o início de um novo negócio, sua sobrevivência e crescimento futuro dependem delas. Similar ao problema de empreendedorismo, definir redes sociais empreendedoras (entrepreneurial networks) e seus tipos é uma tarefa difícil (SZERBG, 2003). As redes sociais empreendedoras são definidas como relações e contatos dos empreendedores com outras pessoas. Tais contatos fornecem meios para reconhecer oportunidades, obtenção de recursos, como também facilidade de utilização de outros recursos, que são potenciais fontes de vantagem competitiva (BIRLEY, 1985; BARNIR e SMITH, 2002).

O ponto de partida para o estudo de empreendedorismo através de redes sociais é a relação ou transação entre duas pessoas (ALDRICH, REESE e DUBINI, 1989). A teoria de rede social está relacionada com empreendedorismo como um processo empreendedor pelo qual os empreendedores procuram oportunidades sem levar em conta os recursos que eles controlam atualmente (STEVESON e JARILLO, 1990, apud LI, 2004), envolvendo o agrupamento de recursos escassos de suas redes de relacionamentos (BIRLEY e CROMIE, 1988).

Aldrich e Zimmer (1986) visualizaram o processo empreendedor como fundamentado em uma rede mutável de relações sociais contínuas que facilitam e compelem ligações entre empreendedores aspirantes, recursos e oportunidades. Para esses autores, a formação de um novo negócio é parte de um processo evolucionário de variação, seleção, retenção, difusão e luta pela sobrevivência.

Embora reconhecendo que indivíduos são intencionais ou propositais em suas ações, esses autores argumentaram que a crescente evidência de limites cognitivos do comportamento humano e a "poderosa influência de fatores sociais nas cognições e processo de informação" significam que alguém não pode atribuir a formação de novos negócios a um indivíduo.

Alguns autores como Johannisson (1998), Birley, Cromie e Myers (1990), Shaw e Conway (2000) destacam que as redes pessoais criadas pelos empreendedores cumprem vários papéis, incluindo a provisão de suporte social, estendendo competências estratégicas pela identificação de ameaças e oportunidades e completando recursos internos para solucionar problemas particulares.

Para Birley e Cromie (1988), a teoria da rede social baseia-se em duas premissas básicas. Primeira, o processo empreendedor envolve o agrupamento de recursos escassos do ambiente; e segunda, os recursos são usualmente obtidos através da rede pessoal dos empreendedores. Assim, novos negócios são criados como resultado de empreendedores motivados, que encontram nichos de oportunidades e obtêm acesso a recursos. Frequentemente os empreendedores requerem informação, capital, habilidade e trabalho para iniciar novas atividades de negócios. Muitos destes recursos eles mesmos retêm, mas geralmente complementam os seus recursos, físicos ou não, entrando em contato com outros indivíduos, procurando ajuda com amigos, familiares, colegas de trabalho e com outras pessoas fora de seu círculo de convivência social (BIRLEY, 1985; ALDRICH e ZIMMER, 1986). 
Esses contatos realizados têm como objetivo não só obter os recursos econômicos para iniciar o negócio, como também buscar apoio para a ideia do negócio, conselhos, e informações, e apoio social e emocional para a constituição do empreendimento (JOHANNISSON, 1998; BARNIR e SMITH, 2002).

Johannisson (1990, p. 3) destaca: “Alguns desses recursos podem prover soluções diretas para os problemas operacionais, enquanto outros aumentam a legitimidade da empresa no mercado e indiretamente fornecem acesso aos recursos necessários para a busca dos objetivos econômicos", assim, a rede social do empreendedor é estrategicamente o recurso mais significativo da empresa.

Percebe-se que, no começo de um novo empreendimento, a rede social é um ativo crucial para os donos de negócios, que lutam para alcançar um lugar em mercados mais competitivos, ou seja, no processo de criação de negócios, os indivíduos mobilizam sua rede de relações pessoais para obter recursos (físicos, informação, suporte emocional, capital, contatos de negócios etc.) e transformar visões e planos de negócio em realidade (BIRLEY, 1985; ALDRICH e ZIMMER, 1986; JOHANNISSON, 1998, 2000).

Para Mizumoto et al. (2008), quanto maior a ligação a membros familiares, amigos, parceiros comerciais, etc., maior o acesso a recursos valiosos, informações, recursos financeiros, conhecimentos, que devem aumentar a probabilidade de sobrevivência do empreendimento. Essa mobilização de relacionamentos pessoais denota o processo de construção social das atividades econômicas (GRANOVETTER, 1985), e a dependência que os indivíduos têm de sua rede para obter recursos (ALDRICH e ZIMMER, 1986; ALDRICH, ROSEN e WOODWARD, 1987; HANSEN, 1995; JOHANNISSON, 2000) que, por variadas razões, não estão disponíveis internamente na empresa (OSTGAARD e BIRLEY, 1994), e que, de outra forma, não seriam facilmente acessados.

Johannisson et al. (1994) citam que a confiança em redes não é compelida pela fase inicial dos negócios, e que nas demais fases, nota-se que os empreendedores continuam confiando em redes para conselhos, informações de negócios e resolução de problemas, através de alguns contatos que proveem múltiplos recursos.

Existem vários estudos sobre redes sociais no campo do empreendedorismo e eles têm mostrado que redes entre empreendedores desempenham importante papel no processo empreendedor de estabelecer e administrar um novo negócio (BIRLEY, 1985; ALDRICH e ZIMMER, 1986; ALDRICH e DUBINI, 1991; OSTGAARD e BIRLEY,1996; JOHANNISSON, 1998; GREVE e SALAFF, 2003; BORGES, SIMARD e FILION, 2005; BORGES, 2007).

Ostgaard e Birley (1996) realizaram uma pesquisa (survey) na Grã-Bretanha, envolvendo 159 donos-gerentes de empresas, cujo objetivo estava relacionado ao questionamento da efetividade das redes pessoais em termos do desempenho e crescimento da empresa. Como conclusão do estudo, os autores destacam que os empreendedores que devotam mais tempo no desenvolvimento de contatos com outros novos investidores tendem a administrar empresas com alto crescimento.

Reyes Junior (2008), em um estudo realizado com 250 empresas, considerou que as relações sociais, internas e externas impactam na eficiência das organizações. Ainda, destacou que a base dessas relações é a confiança, que é ao mesmo tempo elemento formador e estruturador do conjunto de relações.

Borges (2005) destaca que a importância da formação de redes empresariais é notável para as empresas, mais especificamente para as pequenas e médias, onde a chave que dá acesso à competitividade pode estar nas redes de contatos, compostas por outras empresas, ou por atores com quem o empreendedor e sua organização mantêm relações para obter recursos diversos, sejam materiais ou imateriais, necessários para completar os próprios recursos internos.

O referido autor afirma que a informação que circula em uma rede de contatos é compartilhada exclusivamente pela interação humana, na relação entre indivíduos ou organizações. Essa interação é 
essencial para os empreendedores, que precisam descobrir possibilidades e mobilizar recursos mais efetivamente que os outros.

Quando as pessoas frequentemente seguem muitos ciclos de atividades repetitivas, com rotinas diárias que dominam suas vidas, tendem a ficar absorvidas em suas próprias atividades não conectadas a outras pessoas, deixando assim que oportunidades lucrativas passem de forma despercebida (ALDRICH, ELAM e REESE, 1996).

O estudo realizado por Borges (2005), com 14 empresas da indústria do vestuário do estado de Goiás, sobre empreendedores e mais especificamente sobre suas redes de relacionamento, chama a atenção para o papel dos laços como fontes de informações importantes para o processo de inovação empreendedora. Como principais resultados, ele constatou que a contribuição das redes às pequenas e médias empresas (PMEs) se realiza de três formas: 1) as redes são uma fonte de informações; 2) as redes são uma fonte de ideia e de comparação; e 3) as redes melhoraram a capacidade de adaptação das PME’s em um ambiente de constantes mudanças.

\section{Capital Social}

O conceito de capital social tem chamado muita a atenção de uma gama extensa de acadêmicos nos últimos anos. Ele é caracterizado pelas contribuições de uma variedade de disciplinas, incluindo ciências políticas, sociologia, teoria organizacional e estudos de gerenciamento. Nas ciências sociais, também se tem tornado crescentemente popular em várias disciplinas e desse modo, de acordo com Adler e Know (2002), nos estudos de organização, também, o conceito de capital social está ganhando aceitação.

Embora as ideias de capital social tenham sido largamente discutidas em uma variedade de literatura (ou talvez em parte, devido às diversas abordagens para ele), o conceito, de acordo com Adler e Kwon (2002, p.18), ainda está em 'empolgação emergente' do ciclo de vida típico de um conceito "guarda-chuva".

Avaliando a evolução e as diferenças no conceito de capital social, Portes (1998, p.6) salienta que "apesar das diferenças, o consenso é crescente na literatura que capital social se afirma como a habilidade de atores de garantir benefícios em virtude de sua associação em redes sociais e outras estruturas sociais".

O desenvolvimento recente do conceito de capital social nas ciências sociais é tipicamente associado aos nomes como Pierre Bourdieu (1986), James Coleman (1990) e Robert Putnam (2000). Todos eles enfatizam o papel das redes sociais, confiança, normas e sanções facilitando a ação coletiva.

O reconhecimento do valor das relações como recurso, tanto para atores individuais quanto para atores coletivos, não significa tratar-se de uma ideia nova. A primeira utilização conhecida do conceito "capital social" para expressar valor é mais recente, é datada de 1916. O sociólogo francês Pierre Bourdieu, no final dos anos 1960 e início dos 1970 foi o primeiro que utilizou o conceito de capital social de maneira sistemática (PORTES, 1998). A capacidade de ação de um agente, ou um indivíduo, segundo Bordieu (1980, 1986), ou um negócio não depende somente de recursos financeiros ou tangíveis que possui, mas de seus diferentes recursos, incluindo os intangíveis. Depois de um tempo, Bourdieu (2000) indica as outras formas de capital: capital simbólico, tecnológico e comercial. Após Bourdieu, outro autor que se destacou pelos estudos sobre este assunto foi Coleman $(1988 ; 1990)$, que trata do papel do capital social dentro do desenvolvimento do capital humano, e em seguida veio Robert Putnam. Foi nos fim dos anos 90, depois dos escritos de Coleman e Putnam, que o conceito de capital social se popularizou (BORGES, 2007).

Putnam (1995, p. 67) inicialmente definiu capital social como "características de uma organização social tais como redes, normas e confiança social que facilitam a coordenação e cooperação em benefício mútuo". 
Entretanto, em trabalhos mais recentes, Putnam (2000) localizou a confiança como resultado do capital social definido como redes sociais e normas associadas de reciprocidade. Ele distingue isto como uma definição estreita 'enxuta e boa' em contraste com uma definição mais ampla, que inclui aspectos de cultura, crenças e instituições 'uma grande tenda'.

Nota-se que teóricos têm discordado sobre a definição e interpretação do termo capital social. Putnam e Bourdieu têm dois conceitos diferenciados de capital social. Para Putnam (2000), o capital é um conjunto de recursos possuído pelo grupo, enquanto, para Bourdieu (1986), é uma consequência das relações sociais, que é percebida pelos envolvidos in abstracto; deste modo, é passível de ser transformado por eles em outra forma de capital. Observa-se que Bourdieu (1986) e Putnam (2000) usam o grupo como nível de análise, em seus argumentos de que grupos coletivamente aumentam as chances de vida de seus membros através do capital social. Lin (2001a), por sua vez, usa o indivíduo como uma unidade de análise para argumentar que o capital social é um instrumento para negócios e que trabalha de forma similar aos investimentos em capital humano.

Coleman (1988) pareceu usar o termo com ambas as referências: coletiva e individual. Ele via capital social como fonte para a ação social, que poderia levar à aquisição de outras formas de capital, humano e físico. De forma similar, Burt (1992) define capital social como a qualidade criada entre pessoas. Renzulli, Aldrich e Moody (2000) usam o capital social para indicar as características dos laços pessoais de uma pessoa com outras que pode fornecer acesso a importantes recursos.

Nota-se que o crescimento rápido da utilização do conceito de capital social não foi acompanhado de uma definição consensual sobre seu significado. Dessa forma, apesar dessa variedade de entendimentos e concepções sobre o tema, é possível identificar dois elementos comuns: nível de confiança estabelecida entre os membros de uma organização ou ainda a coesão social de uma nação e rede de relacionamentos de um indivíduo (BORGES, 2007).

Burt (1992, 1997, 2001) amplia as considerações de Granovetter sobre "ligações (ou laços) fracas" e procura conceber um modelo de competição econômica, baseado na estrutura do relacionamento social e no conceito de "buraco estrutural", onde o capital social é um resultado de uma rede na qual as pessoas podem trocar conexões entre segmentos desconectados. Estas conexões são mais parecidas com uma ponte de capital social e facilitam acesso fácil e rápido a diferentes segmentos de informação e conhecimento entre as fronteiras técnica e social.

O que interessa em uma rede, segundo Burt (2001, p. 29), não é, exatamente, "a força do vínculo fraco, mas, o buraco estrutural que esta é capaz de atravessar" e o número de contatos não redundantes. As lacunas são vislumbradas, no contexto empresarial, como oportunidades a serem preenchidas por um terceiro elemento, o empreendedor. $\mathrm{O}$ empreendedor é a pessoa capaz de agregar valor à atividade produtiva, intermediando as conexões entre as outras. Na essência do empreendedorismo situa-se a habilidade de colocar juntas peças de outra maneira desconectadas. Nessa acepção, as vantagens competitivas do empreendedor estariam associadas à sua capacidade de acesso a tais buracos no mercado, garantida por uma rede de laços e conexões.

Lin (2001b) declara que a noção de capital social como investimento em relações sociais espera retorno, capital social é visto como o benefício que pode ser derivado da rede social. É neste sentido que também Recuero (2004) entende o capital social, este se constitui no conteúdo das relações sociais em uma rede, ou seja, trata-se do conteúdo embutido nas interações que constituem os laços sociais, que podem ser acumulados, aprofundando um determinado laço e aumentando o sentimento de grupo.

As relações entre os atores sociais estão no meio dos estudos em capital social e as abordagens das redes sociais são utilizadas para operacionalizar as investigações empíricas em capital social (BORGATTI e FOSTER, 2003). A ideia principal do conceito de capital social é que a rede social (ex. famílias, amigos e 
conhecidos) tem valor (PUTNAM, 2000). O capital social é produzido pela estrutura das relações sociais e pode ser mobilizado para facilitar ações (ADLER e KWON, 2002), sendo a sua adequação uma importante característica, fato que um tipo de rede social pode ser frequentemente usado para diferentes propósitos.

Davidisson e Honig (2003) utilizam amplamente o capital social em termos de troca social, para examinar os efeitos da troca de ligações no desempenho. Efeitos de trocas podem variar da provisão de recursos concretos, como um empréstimo feito por uma mãe para sua filha até recursos intangíveis, tais como informações sobre a localização de um novo cliente em potencial. Outro aspecto do capital social é o princípio de reciprocidade generalizada. "Eu farei isto para você agora, sem esperar nada imediatamente em troca e talvez sem conhecer você, confiante que mais para frente, você ou outra pessoa retornará este favor" (PUTNAM, 2000, p. 134).

Adler e Kwon (2002) mencionam duas perspectivas maiores dentro dos estudos que utilizam o conceito de capital social: perspectiva externa (quando a atenção é colocada nas relações externas de um ator) e a perspectiva interna (quando a atenção é colocada nas relações internas de um grupo ou de uma comunidade). Nota-se que existe outra terminologia para nomear as perspectivas externas e internas: perspectiva bridging e perspectiva bonding. Alguns autores pertencem ao primeiro grupo da perspectiva externa (BORDIEU, 1986; PORTES, 1998); outros pertencem ao grupo da perspectiva interna (COLEMAN, 1988; PUTNAM, 2000) e ainda há os que abordam as duas perspectivas (NAHAPIET e GHOSHAL, 1998).

Contudo, Putnam (2000) utiliza os termos bridging e bonding de uma maneira ligeiramente diferente. Para este autor, o capital social bonding é constituído das relações mais densas em conteúdo emocional e cultural (aqueles que o indivíduo tem com os membros de sua família, grupo ético ou de igreja, então dentro de um mesmo grupo social) e que normalmente traz suporte social e psicológico. E o capital social brinding por sua vez é constituído de relações dos indivíduos com os atores de um grupo social diferente do seu. As relações bridging dão acesso a recursos e informações mais variadas.

Além das divisões externa/interna ou bonding / bridging, outra maneira de identificar diferentes perspectivas do capital social é usada por Lin (2001b). Este autor indica que existem duas perspectivas maiores de capital social: capital social coletivo e capital social individual. As duas perspectivas são baseadas no nível que será favorecido graças às repercussões, ou retornos do capital social: um ator coletivo ou um ator individual.

Segundo Nahapiet e Ghoshal (1998), o capital social é multidimensional, e ocorre nos níveis individual e organizacional. Esses autores enfatizam que o capital social comporta três dimensões relacionadas: a dimensão estrutural (ligações e configurações da rede), a dimensão relacional (a confiança, as normas, obrigações e a identificação com o grupo) e o aspecto cognitivo (as representações e interpretações compartilhadas).

Lin (2001b) declara que a noção de capital social como investimento em relações sociais espera retorno; capital social é dessa forma visto como o benefício que pode derivar de redes sociais. $\mathrm{O}$ autor ainda considera o capital social como um conjunto de recursos tangíveis ou virtuais que advêm para os atores através da estrutura social, facilitando a realização dos seus objetivos. Lin (2001b), preocupado em explicitar as vantagens advindas com a "posse de uma rede de relações", salienta alguns dos benefícios que o capital social pode oferecer a um indivíduo e que constituem uma diferença entre capital social e os outros tipos de capitais: humano, natural, financeiro, físico.

No mesmo sentido que Lin, Adler e Kwon (2002) indicaram a informação, a influência e a solidariedade como principais benefícios do capital social. Adler e Kwon (2002) destacam, por exemplo, que o capital social facilita o acesso a fontes mais amplas de informações e melhora a qualidade das informações, relevância e linha do tempo. Além disso, o alto custo da aquisição da informação, normalmente existente, pode ser reduzido através do capital social (COLEMAN, 1988). 


\section{Metodologia}

\section{Classificação e estratégia da pesquisa}

Em função de sua proposta, esta pesquisa pode ser classificada como de caráter qualitativo, pois irá considerar uma relação dinâmica entre o mundo real e o sujeito, não requerendo métodos e técnicas estatísticas; conforme cita Godoy (1995), para entender a dinâmica do fenômeno, é necessário coletar e analisar diversas informações. Os atores sociais envolvidos na pesquisa serão levados a refletir sobre suas ações e sobre as consequências dessas ações para a realidade em que estão insertos.

A estratégia de pesquisa escolhida para este estudo foi o estudo de casos, pois permite o entendimento do fenômeno como um todo, com profundidade. Segundo Yin (2001, p.32), o estudo de caso é "uma investigação empírica que investiga um fenômeno contemporâneo dentro de seu contexto da vida real, especialmente quando os limites entre o fenômeno e o contexto não estão claramente definidos". O autor cita que este tipo de estudo tem se tornado a estratégia mais utilizada quando os pesquisadores procuram responder questões do tipo "como" e "por que".

Quando a pesquisa envolve duas ou mais pessoas, duas ou mais organizações, pode ser considerado um estudo de casos múltiplos. Primeiramente a teoria é desenvolvida; depois são feitas a seleção dos casos e a definição dos métodos de coleta de dados. Há necessidade de realizar um estudo completo de cada caso, bem como desenvolver um relatório individual, detalhando como e por que uma determinada proposição foi ou não apresentada. O objetivo pode ser o de estabelecer comparações, ou de descrever mais de um indivíduo, instituição, ou evento (GODOY, 1995).

Conforme cita Eisenhardt (1991), diferentes casos frequentemente enfatizam os aspectos complementares do fenômeno. Reunindo os padrões individuais, o pesquisador pode extrair um retrato teórico mais completo. Para Yin (2001), a lógica que predomina no estudo de casos múltiplos é a da replicação, semelhante àquela usada em experimentos múltiplos. Cada caso deve ser selecionado com o objetivo de: a) prever resultados semelhantes (uma replicação literal); ou b) produzir resultados contrastantes apenas por razões previsíveis (uma replicação teórica). Para esse autor, apesar de o estudo de casos múltiplos exigir mais tempo e recursos, os resultados provenientes dessa estratégia são considerados mais convincentes e robustos.

\section{Coleta de Evidências}

Sendo a entrevista uma das técnicas de interrogação que apresenta maior flexibilidade, é uma das mais importantes fontes de evidência para um estudo de caso (YIN, 2001). Assim, em função desta flexibilidade, permite ao pesquisador incluir e excluir determinadas questões, ou ainda efetuar alterações na ordem das questões, em virtude das respostas obtidas. Para esse estudo foi utilizado roteiro semiestruturado de entrevistas, permitindo ao entrevistado flexibilidade em suas opiniões.

Foram realizadas entrevistas com cada um dos sócios empreendedores das empresas selecionadas, com a duração média de duas horas cada uma, nos meses de julho e agosto de 2008. Todas as entrevistas foram gravadas e posteriormente transcritas e analisadas. Trivinos (1987) recomenda a gravação da entrevista porque permite contar com todo o material fornecido pelo informante, o que não ocorre seguindo outro meio.

Embora as entrevistas constituam fonte essencial de informações para um estudo de caso, Yin (2001) recomenda corroborar os dados obtidos com outras fontes de evidências. Assim, foi realizada a observação como fonte de coletas de evidências e a análise de documentos. Foram observadas as instalações físicas das empresas, a equipe de funcionários e o funcionamento operacional dessas empresas. Alguns dos documentos utilizados neste trabalho foram documentos administrativos, relatórios e folders formulados pelas empresas 
pesquisadas, além de informações sobre essas instituições disponíveis em matérias publicadas na mídia: reportagens em jornais e internet.

Os dois municípios escolhidos pertencem à região norte pioneiro do Paraná; um trata-se do município de Cornélio Procópio, que tem 48.427 habitantes, e o outro é Cambará, que fica a $45 \mathrm{~km}$ de Cornélio Procópio, e tem 24.902 habitantes. Primeiramente foi escolhido o município de Cornélio Procópio, mas como um dos empreendimentos escolhidos tem a matriz em Cambará, este município foi incluído.

O primeiro caso é da Escola Técnica de Enfermagem, uma empresa de pequeno porte, estabelecida em Cornélio Procópio, criada em 1999 e com um quadro de 18 funcionários, incluindo a empreendedora com formação acadêmica em enfermagem. O segundo é o de uma empresa de desenvolvimento de software, préincubada no hotel tecnológico da UTFPR (Universidade Tecnológica Federal do Paraná), campus de Cornélio Procópio, que foi constituída inicialmente por alunos graduandos do curso de Tecnologia em Sistemas de Informação, em 2004, e que atualmente tem trinta funcionários. Já o terceiro caso, trata-se de uma agência do ramo de turismo, criada em 2001 pelo casal Reinaldo e Leomara, que possui cinco funcionários e está estabelecida em Cambará e com uma filial em Cornélio Procópio.

\section{Protocolo do estudo de caso}

Considerado por Yin (2001) como outro instrumento que tem a finalidade de dar maior confiabilidade à pesquisa, bem como estabelecer os instrumentos e as estratégias de ação que deverão ser seguidas pelo pesquisador, o protocolo do estudo de caso tem o objetivo de facilitar o desenvolvimento do trabalho de campo. Procura-se elencar nesse protocolo os procedimentos que foram adotados de forma que facilite a replicação da pesquisa por outros pesquisadores interessados no tema da pesquisa.

- Escolher as empresas/casos para a realização de um estudo de caso piloto.

- Elaborar o roteiro prévio das entrevistas.

- Realizar o estudo de caso piloto.

- Analisar as informações obtidas no estudo de caso piloto.

- Adequar o roteiro para realização das entrevistas semiestruturadas.

- Definir as empresas/casos a serem estudadas.

- Agendar as entrevistas com os empreendedores responsáveis pela empresa.

- Realizar a entrevista e a observação direta durante a visita em cada empresa.

- Analisar os documentos das empresas.

- Analisar as informações provenientes das entrevistas, das observações e dos documentos, individualmente.

- Descrever os casos de cada empresa.

\section{Definições constitutivas, categorias analíticas e elementos de análise}

Nesse estudo, a definição constitutiva de capital social parte do pressuposto que a rede social (ex. famílias, amigos e conhecidos) tem valor (PUTNAM, 2000). O Capital Social é, portanto, gerado pelo tecido de relações sociais e pode ser mobilizado para facilitar ações (ADLER e KWON, 2002). É nesse sentido que, nesta pesquisa, entende-se o capital social como o conteúdo embutido nas interações que constituem as 
ligações ou laços sociais, que pode ser acumulado, aprofundando um determinado contato. Operacionalmente neste estudo, o capital social deve ser entendido a partir da utilização das redes sociais para a criação de valor que contribuem para o alcance dos objetivos dos empreendedores.

As redes sociais empreendedoras são definidas como relações e contatos dos empreendedores com outras pessoas. Tais contatos fornecem meios para reconhecer oportunidades, obtenção de recursos, como também facilidade de utilização de outros recursos, que são potenciais fontes de vantagem competitiva (BIRLEY, 1985; BARNIR e SMITH, 2002; LI, 2004).

O quadro 1 apresenta as categorias analíticas e os elementos de análise que definem operacionalmente os tipos de redes sociais e os recursos que são acessados através das redes sociais.

\section{Quadro 1}

\section{Categorias Analíticas e Elementos de Análise}

\begin{tabular}{|c|c|}
\hline Categorias Analíticas & Elementos de Análise \\
\hline $\begin{array}{l}\text { Tipos de redes sociais para a } \\
\text { criação e o } \\
\text { desenvolvimento do } \\
\text { negócio }\end{array}$ & $\begin{array}{l}\text { Formais - Pessoas que mantêm ligações diretas ou assuntos referentes a } \\
\text { negócios (bancos, contadores, advogados, consultores e organizações). } \\
\text { Informais - Envolvem família, amigos, antigos colegas e empregados (BIRLEY, } \\
\text { 1985). }\end{array}$ \\
\hline Categorias Analíticas & $\begin{array}{l}\text { Recursos Sociais } \\
\text { Suporte emocional, moral e técnico; Identificação de novas oportunidades de } \\
\text { negócio e ameaças;Suporte motivacional; Reputação; Legitimidade; Relação de } \\
\text { Confiança; Status; Fonte de ideias e informações; Conselhos; Compartilhamento } \\
\text { de conhecimento e experiências entre atores envolvidos; } \\
\text { Indicações de fornecedores, clientes e funcionários pelos contatos } \\
\text { intermediários;Capacidade ou habilidade adquiridas ou fortalecidas; } \\
\text { (BIRLEY, 1985; ALDRICH e ZIMMER, 1986; ALDRICH, ROSEN e WOODWARD, 1987; } \\
\text { OSTGAARD e BIRLEY, 1994; JOHANNISSON, 1998; COOPER, 2000; SHAW e } \\
\text { CONWAY, 2000; HITE, 2001; LIN, 2001b; BARNIR e SMITH, 2002; ADLER e KWON, } \\
\text { 2002; ALDRICH E CARTER, 2004; VASCONCELOS, 2004; BORGES, 2005, 2007) }\end{array}$ \\
\hline \multirow{2}{*}{ Cursos Acessados } & $\begin{array}{l}\text { Recursos Financeiros } \\
\text { Empréstimos e financiamentos; orçamento; procura por investimentos; aplicação } \\
\text { dos recursos; custos fixos (matérias-primas e fornecedores, equipamentos, } \\
\text { locações e funcionários). (BIRLEY, 1985; CHU, 1996; BORGES, 2007). }\end{array}$ \\
\hline & $\begin{array}{l}\text { Recursos Físicos } \\
\text { Matérias-primas e insumos, máquinas e equipamentos, veículos, imóveis e } \\
\text { localização física (VASCONCELOS, 2004). }\end{array}$ \\
\hline
\end{tabular}

Fonte: Desenvolvido pelas autoras com base na revisão teórica apresentada. 


\section{Análise dos Casos}

Inicialmente, é apresentada uma breve descrição de cada uma das empresas e dos seus empreendedores e depois são apresentados para cada empresa quadros resumos dos tipos de redes nas fases de criação e desenvolvimento do novo negócio e recursos acessados nessas fases escolhidos a partir dos depoimentos dos entrevistados.

\section{Caso 1- Escola Florence}

O primeiro caso analisado é o Centro de Educação Profissional Florence, uma escola de ensino médio voltada para a formação de técnicos em enfermagem. Foi fundada em 12.05.1999, na cidade de Cornélio Procópio, Paraná. A sua criação deu-se pela necessidade de aperfeiçoar e desenvolver a formação de profissionais auxiliares de enfermagem que trabalhavam na Santa Casa da cidade, bem como a necessidade da formação de um quadro de funcionários técnicos em enfermagem e de enfermeiros capacitados que pudessem oferecer um atendimento de qualidade para a população da região.

O referido centro foi criado pela empreendedora Alexsandra, que tem formação acadêmica em Enfermagem. Tem, no seu quadro de funcionários, 18 professores, 3 funcionários administrativos e, conta com uma média de 120 alunos pertencentes às diferentes cidades da região (Sertaneja, Leópolis, Uraí, Abatiá, Cambará, Itambaracá, Bandeirantes e outras). Desde sua criação formou 22 turmas com uma média de 40 alunos em cada turma.

A empreendedora Alexsandra, durante sua formação em Enfermagem pela Universidade Estadual de Londrina, Paraná, começou sua carreira fazendo estágios em alguns hospitais de Londrina e, depois de efetivada, trabalhou alguns anos na Santa Casa e no Hospital Evangélico de Londrina, adquirindo experiência e conhecimento.

Por motivos particulares, a enfermeira retornou para Cornélio Procópio, cidade em que nasceu, e começou a trabalhar no departamento de saúde da prefeitura de uma cidade vizinha, Assaí, mas sentia que estava faltando algo na sua vida, como destacou na entrevista: "comecei a trabalhar no hospital de Assaí, mas era muito tranqüilo e era muito pouco para mim, e eu não consigo ficar com pouco".

Ao ficar sabendo de uma vaga de enfermeira na Santa Casa de Cornélio Procópio, candidatou-se, e começou a trabalhar também na prefeitura de Cornélio Procópio. Na entrevista de contratação, ao saber do salário (inferior ao que ganhava nos empregos anteriores), convenceu o provedor da Santa Casa, o médico JC, a aceitar uma proposta de trabalho, propondo-se a trabalhar por três meses para o hospital; no fim desse período, o provedor ou o hospital fariam uma avaliação de seu trabalho e voltariam a negociar o salário.

Foi então trabalhando também na Santa Casa de Cornélio Procópio que começou a perceber que muitas coisas funcionavam de forma bem diferente do que nos hospitais onde havia trabalhado. Deparou-se com uma estrutura hospitalar e uma Unidade de Tratamento Intensivo (UTI) com carência de recursos ou com recursos inadequados e, ainda, com profissionais (técnicos e auxiliares de enfermagem) despreparados e desprovidos de conhecimentos técnicos adequados. Foi dessa forma que Alexsandra sentiu a necessidade de compartilhar seus conhecimentos de enfermagem com os funcionários da Santa Casa de Saúde, com quem trabalhava diretamente. Observou que determinados pré-requisitos básicos que são exigidos para essa área não estavam sendo atendidos e que a formação dos enfermeiros dependia de um processo formalmente atrelado à escolarização. Começou então a trabalhar no desenvolvimento da capacitação desses funcionários através da realização de alguns cursos, ministrados internamente por ela, pois dizia "Não adianta um hospital ter os melhores equipamentos, a melhor estrutura física, e os melhores médicos, sem ter os recursos humanos, que compõem a equipe, adequadamente treinados". Diante do cenário de carência de profissionais com adequada formação técnica, pois, os treinamentos internos não conseguiam suprir toda a necessidade, e ainda, da dificuldade de contração de bons profissionais, a empreendedora visualizou uma oportunidade de 
negócio e se sentiu motivada com a ideia da criação de uma escola técnica de Enfermagem. O quadro 2 apresenta resumo dos tipos de redes que foram criados pela empresa.

Quadro 2

Resumo dos tipos de redes nas fases de criação e desenvolvimento do negócio

\begin{tabular}{|l|l|l|}
\hline Criação & Formais & $\begin{array}{l}\text { Órgãos governamentais (prefeituras e órgãos ligados à educação e à saúde do } \\
\text { município e do estado). }\end{array}$ \\
\cline { 2 - 3 } & Informais & $\begin{array}{l}\text { Amigos, colegas de trabalho, professores, bancos e fornecedores de } \\
\text { equipamentos e medicamentos de saúde. }\end{array}$ \\
\hline Desenvolvimento & Formais & Órgãos governamentais, órgãos ligados à saúde e bancos. \\
\cline { 2 - 3 } & Informais & $\begin{array}{l}\text { Amigos, colegas de trabalho, professores, fornecedores de equipamentos e } \\
\text { medicamentos de saúde. }\end{array}$ \\
\hline
\end{tabular}

Fonte: Desenvolvido pelas autoras com base na pesquisa de campo.

O quadro 3 apresenta um resumo dos recursos obtidos pelas redes sociais nessas duas fases.

\section{Quadro 3}

Resumo dos recursos obtidos nas fases de criação e desenvolvimento do negócio

\begin{tabular}{|c|c|c|}
\hline Criação & Sociais & 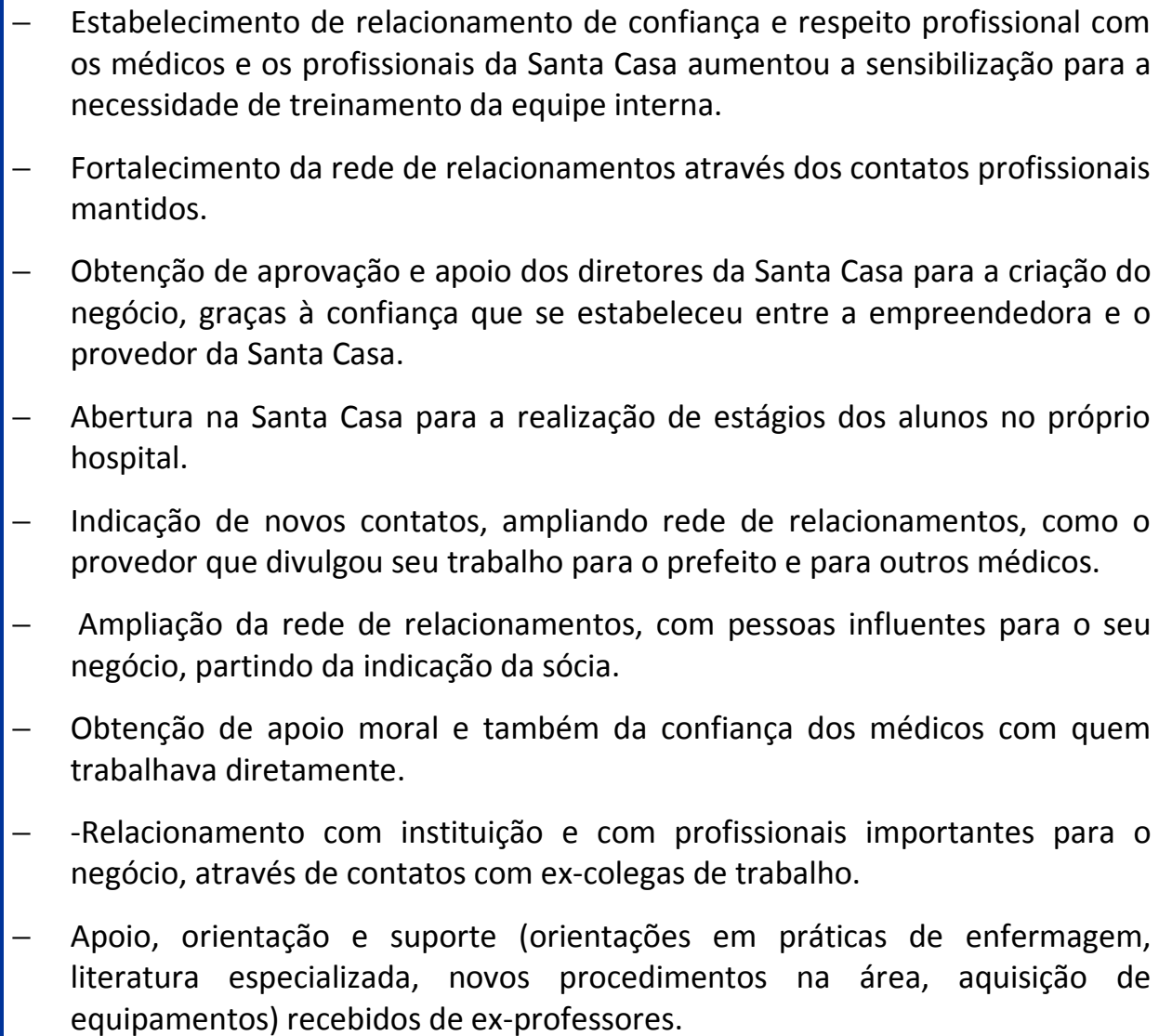 \\
\hline
\end{tabular}




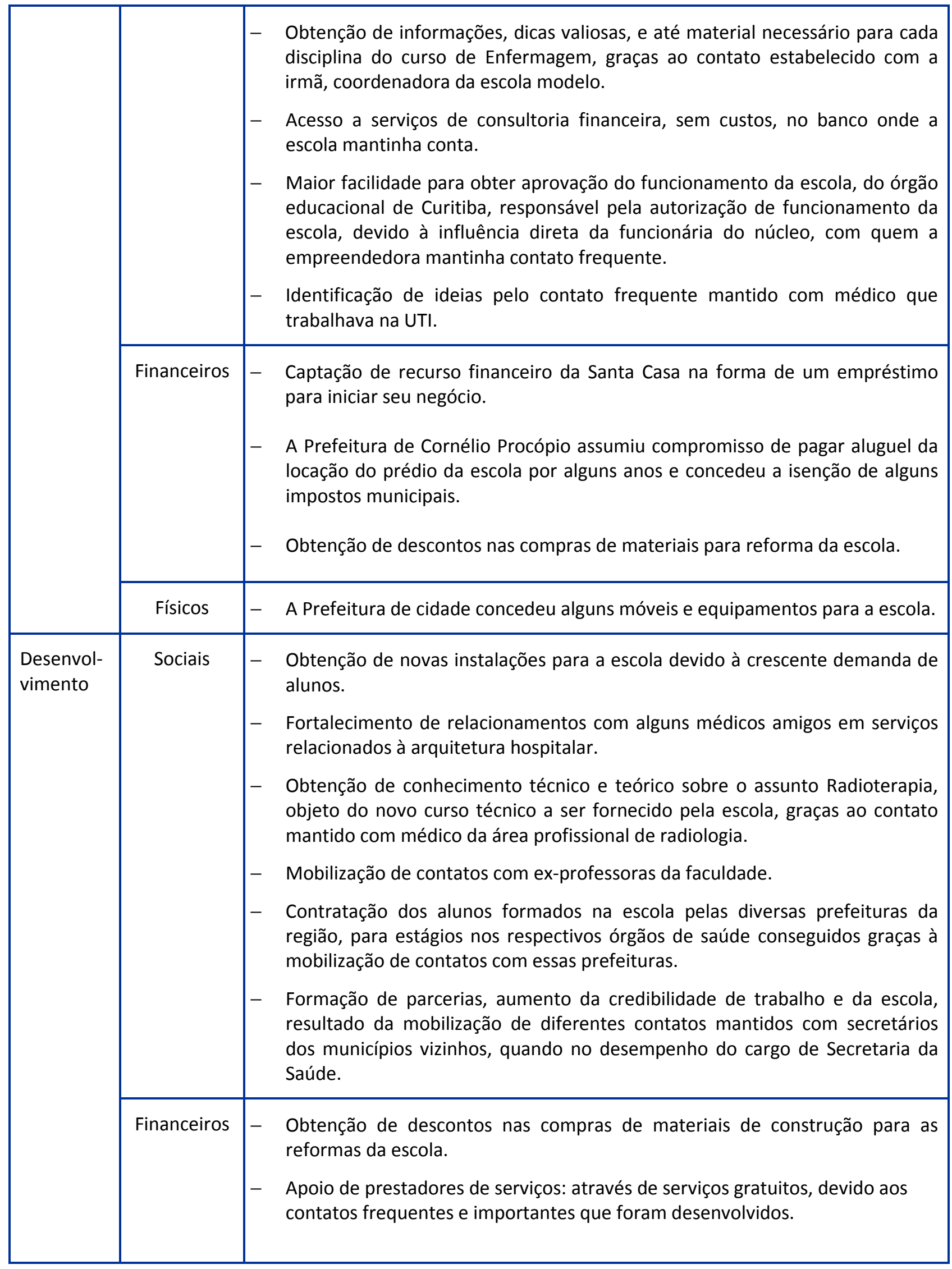




\begin{tabular}{|c|c|}
\hline Físicos & $\begin{array}{l}\text { - Acesso a uma localização estratégica para a instalação da escola, devido a } \\
\text { influência de um dos diretores da Santa Casa. } \\
\text { - } \text { Obtenção de equipamento simulador de raio X para curso técnico de } \\
\text { Radiologia, devido ao contato mantido por longo tempo com um fornecedor. } \\
\text { - Obtenção de bens materiais, equipamentos gratuitos (sonda, autoclave, etc.), } \\
\text { mostras de equipamentos, medicamentos e livros, pelo contato frequente } \\
\text { mantido com diversos fornecedores (representantes de laboratório, } \\
\text { farmácias, médicos). } \\
\text { - Obtenção de ativos importantes para o laboratório da escola. Um médico } \\
\text { amigo desativou seu hospital e forneceu equipamentos e materiais } \\
\text { hospitalares para a escola. }\end{array}$ \\
\hline
\end{tabular}

Fonte: Desenvolvido pelas autoras com base na pesquisa de campo.

\section{Caso 2- ForLogic}

O segundo caso analisado é o caso da empresa de desenvolvimento de software - ForLogic. O caso da empresa de desenvolvimento de software ForLogic relata a trajetória de uma empresa, que foi pré-incubada no Hotel Tecnológico da UTFPR, Campus de Cornélio Procópio, sendo a primeira incubada pela UTFPR desde a fase de projeto. A história teve início com o aluno da UTFPR, Jeison, que em 2001 cursava Tecnologia em Sistemas de Informação. Ele se entusiasmou com a ideia e a possibilidade de ter seu próprio negócio na área de informática e, embora não tivesse em mente o produto ou serviço a oferecer, convidou seu primo, Diogo, também aluno da instituição, para uma sociedade. Ambos compartilhavam o desejo de ter seu próprio negócio e, juntos, começaram a desenvolver o primeiro projeto de informática, um site cuja proposta era montar uma rede social virtual.

A ForLogic Software é uma empresa especializada no desenvolvimento de software, que trabalha com tecnologias de ponta e também atua na criação de soluções de softwares sob encomenda. Foi constituída legalmente em maio de 2004, porém já existia como um projeto do hotel tecnológico instalado na UTFPR, campus Cornélio Procópio, Paraná, desde agosto de 2003. Sua equipe inicial foi formada por quatro estudantes graduandos do mesmo curso.

Atualmente trinta pessoas trabalham na empresa; entre elas há bolsistas, estagiários, funcionários e sócios, os quais têm como missão criar soluções, aumentar a produtividade e reduzir os custos operacionais dos clientes. A empresa mantém uma carteira de 35 clientes, incluindo clientes de outros estados como Mato Grosso, Rio Grande do Sul e São Paulo. Atualmente presta serviços de desenvolvimento de soluções, a pedido, sob demanda para seus clientes, inclusive com atendimento, também a pedido, sob demanda a distância, via internet. Ainda, possui alguns produtos prontos: softwares como gestor do processo metrológico, gestor eletrônico de documentos e informações, controle e acompanhamento de nãoconformidades.

A criação da empresa está fortemente ligada aos dois sócios, Geison e seu primo Diogo, que, em 2003, formaram parceria com outros dois colegas de curso, Reinaldo e Vinícius. Mas a sociedade entre os quatro colegas durou pouco tempo, uma vez que os últimos deixaram a sociedade no final do ano de 2005. Jeison tem 26 anos e é graduado em Sistemas de Informação pela UTFPR, campus Cornélio Procópio. Nasceu em Foz de Iguaçu e mudou-se para Cornélio Procópio em 2000 para estudar na UTFPR. Na cidade natal trabalhou em um negócio da família, uma gráfica, mas iniciou suas atividades profissionais na área de 
assessoria de informática da própria UTFPR. Filho de uma funcionária pública, diz que seguindo o exemplo do pai, um profissional liberal, já falecido, que teve dois negócios próprios, uma gráfica e depois uma transportadora de bebidas, desde o início do curso já tinha bem definida a ideia de ser um profissional liberal e criar seu próprio negócio. Dessa forma incentivou seu primo Diogo, que morava em Boa Vista, em Roraima, a vir prestar exames nessa entidade, para frequentar o mesmo curso e então montarem um negócio juntos.

Diogo aos 19 anos veio de Boa Vista, para estudar na UTFPR, campus de Cornélio Procópio. É graduado em Tecnologia de Sistemas de Informação pela UTFPR, onde se formou em 2005. Também iniciou suas atividades profissionais na UTFPR, como prestador de serviços de assuntos relacionados ao gabinete do diretor da instituição, o que lhe proporcionou um contato frequente com este dirigente. Assim como o primo Jeison, inspirou-se no empreendedorismo do pai, que, por alguns anos, também foi dono de uma gráfica, antes de se tornar um funcionário público, profissão exercida atualmente também pela mãe. Os quadros 4 e 5 apresentam resumo dos tipos de redes que foram criados pela empresa e dos recursos obtidos nas fases de criação e desenvolvimento do negócio.

Quadro 4

Resumo dos tipos de redes nas fases de criação e desenvolvimento

\begin{tabular}{|l|l|l|}
\hline Criação & Formais & Órgãos governamentais (CNPq, UTFPR), APL de TI. \\
\cline { 2 - 3 } & Informais & $\begin{array}{l}\text { Amigos, colegas de escola, professores, noiva, funcionários da UTFPR, } \\
\text { contador. }\end{array}$ \\
\hline Desenvolvimento & Formais & $\begin{array}{l}\text { Órgãos governamentais (CNPq, UTFPR-Universidade Tecnológica Federal do } \\
\text { Paraná em Cornélio Procópio). }\end{array}$ \\
\cline { 2 - 3 } & Informais & $\begin{array}{l}\text { Amigos, colegas de escola, professores, noiva, funcionários da UTFPR, } \\
\text { contador. }\end{array}$ \\
\hline
\end{tabular}

Fonte: Desenvolvido pelas autoras com base na pesquisa de campo.

Quadro 5

Resumo dos recursos obtidos nas fases de criação e desenvolvimento do negócio

\begin{tabular}{|l|l|l|}
\hline Criação & Sociais & $-\begin{array}{l}\text { Oportunidade de criação de sociedade pelo relacionamento com dois } \\
\text { colegas de cursos que estavam instalados no hotel tecnológico. } \\
-\end{array}$ \\
& $\begin{array}{l}\text { Envio dos questionários de pesquisa, facilitado pela ajuda do instrutor do } \\
\text { curso e a força do nome "UTFPR". } \\
-\end{array}$ \\
$\begin{array}{l}\text { Incentivo na realização de treinamentos e na realização de cursos } \\
\text { recebidos pelo coordenador da UTFPR. }\end{array}$ \\
$-\begin{array}{l}\text { Apoio moral e confiança do coordenador do Hotel Tecnológico e da } \\
\text { ouvidora da UTFPR. }\end{array}$ \\
$-\begin{array}{l}\text { Indicação de clientes, feita pelo coordenador do Hotel Tecnológico e pela } \\
\text { gerente de relações empresariais e comunitárias da UTFPR. }\end{array}$ \\
\hline
\end{tabular}




\begin{tabular}{|c|c|c|}
\hline & & 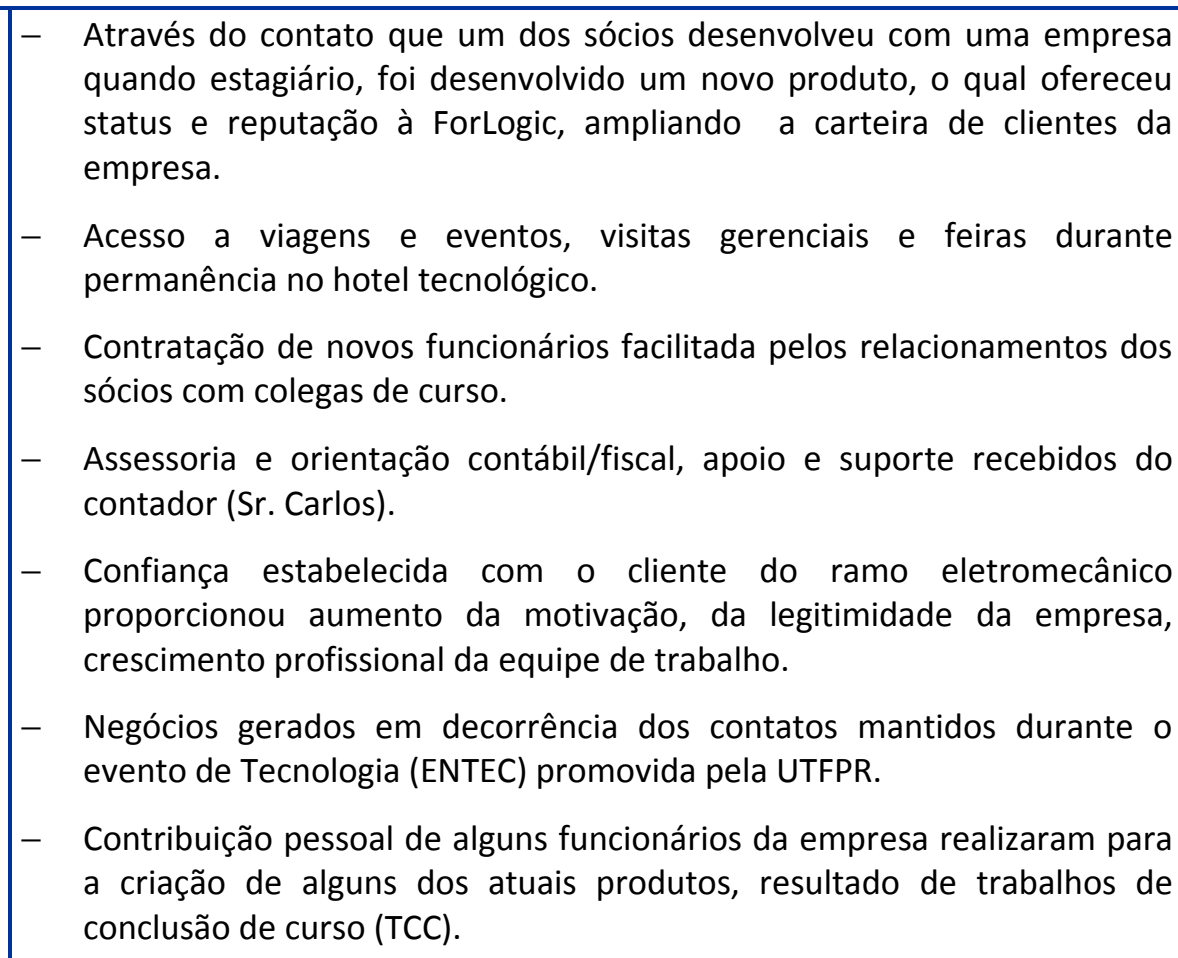 \\
\hline & Financeiros & 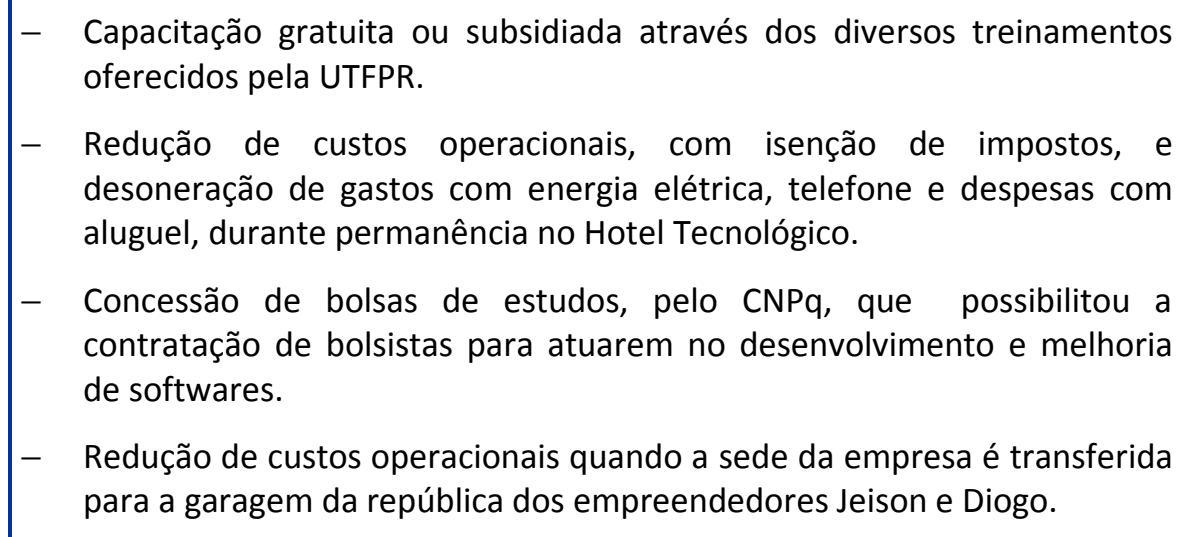 \\
\hline & Físicos & $\begin{array}{l}\text { - Obtenção de um espaço no Hotel Tecnológico através do gerente do } \\
\text { projeto desta instituição. } \\
\text { - O Hotel Tecnológico concedeu alguns móveis e computador para a } \\
\text { empresa pré-incubada. }\end{array}$ \\
\hline $\begin{array}{l}\text { Desenvol- } \\
\text { vimento }\end{array}$ & Sociais & 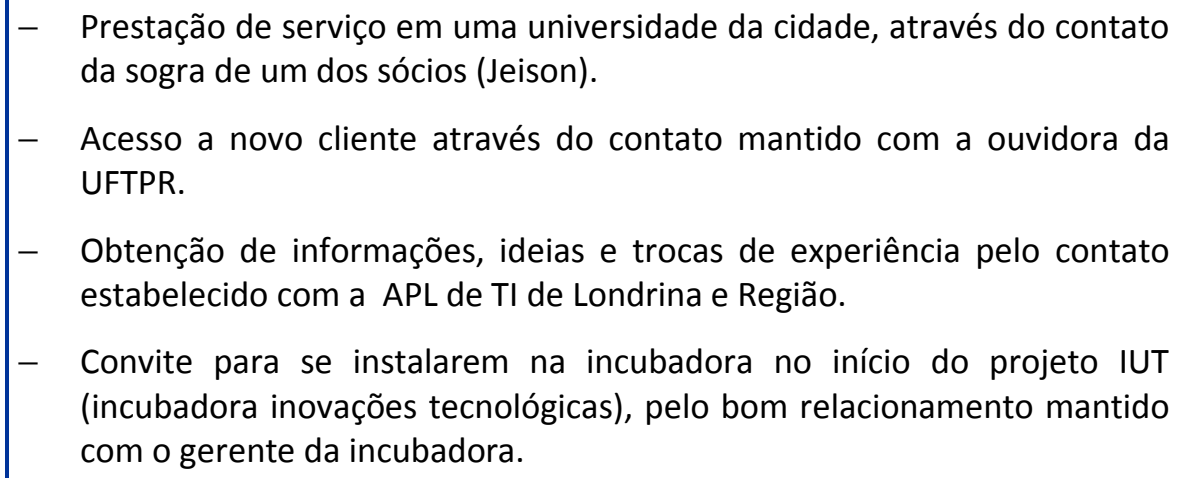 \\
\hline
\end{tabular}




\begin{tabular}{|c|c|}
\hline & 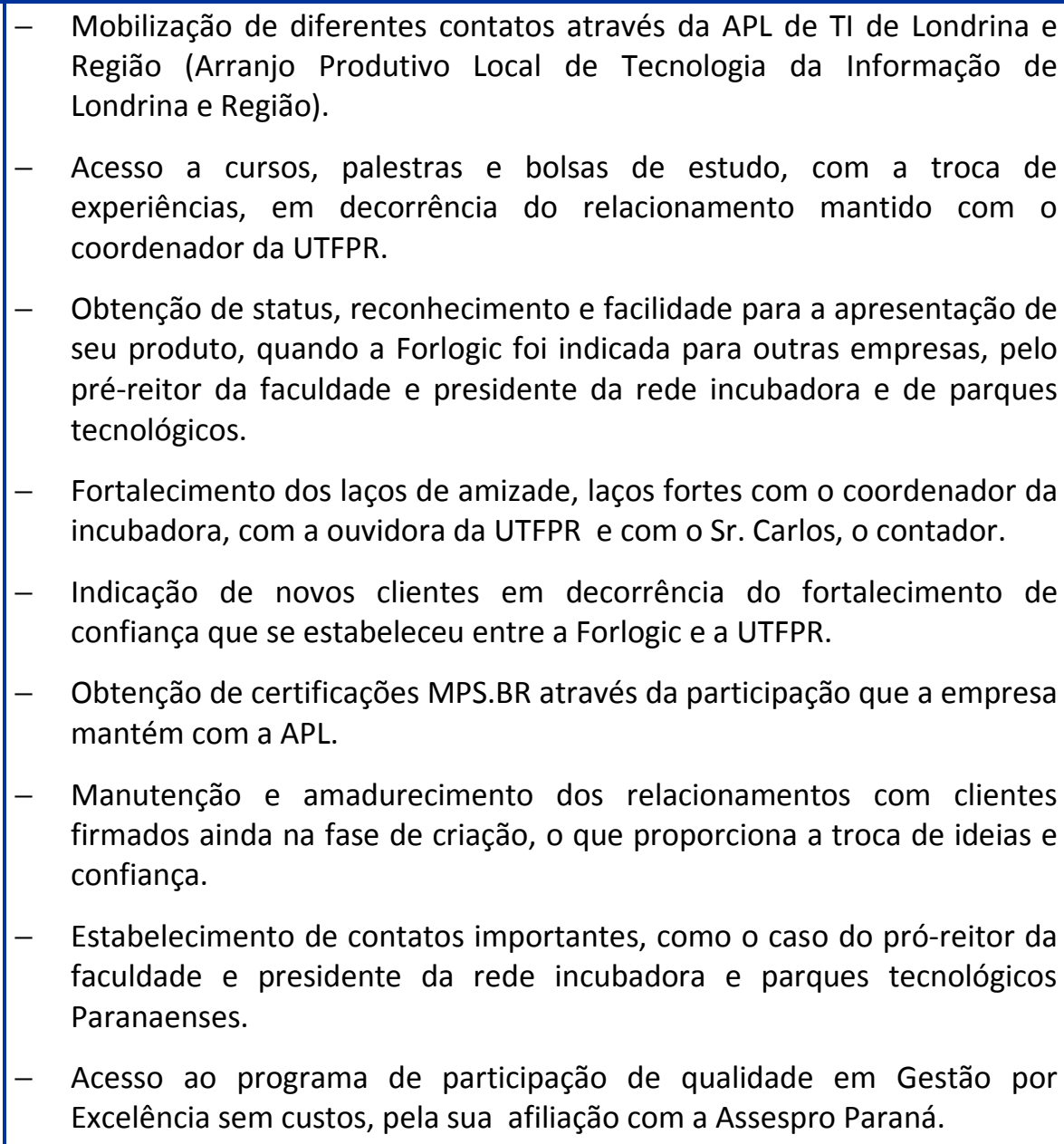 \\
\hline Financeiros & $\begin{array}{l}\text { - Obtenção de isenção de despesas como aluguel, luz e telefone quando } \\
\text { voltam para a Incubadora. }\end{array}$ \\
\hline Físicos & $\begin{array}{l}\text { - Obtenção de uma sede para instalação da empresa na incubadora, graças } \\
\text { à mobilização de contatos com coordenador do projeto e com a UTFPR. }\end{array}$ \\
\hline
\end{tabular}

Fonte: Desenvolvido pelas autoras com base na pesquisa de campo.

\section{Caso 3- Laram Turismo}

O terceiro caso é o da Laram Turismo, que foi criada em 2001, pelo casal Reinaldo e Leomara. É especializada em organizar viagens de férias ou de negócios para qualquer parte do Brasil e do mundo. Trata-se de uma agência de turismo, um agente credenciado da CVC, da venda de cruzeiros marítimos, locação de veículos e assessoria em eventos, que hoje tem cinco funcionários, incluindo os sócios, dois dos quais ficam locados exclusivamente na agência da cidade de Cambará e um na agência de Cornélio Procópio, tendo como missão oferecer segurança e especialidade em seus serviços, vendendo passagens aéreas e rodoviárias, reserva de hospedagem, pacotes turísticos nacionais e internacionais. Atualmente trabalham com pacotes turísticos rodoviários, uma média de quinze por ano, e, ainda, diferentes pacotes turísticos aéreos que geram uma média de 500 contratos anuais, variando de três a quatro clientes por contrato. Sua base de clientes, atualmente, é de 2000 clientes, pertencentes a 70 cidades de diferentes estados brasileiros: São Paulo, Mato Grosso do Sul, Rio de Janeiro e Paraná. 
Leomara tem 37 anos, é formada em Administração de Empresas, com pós-graduação em Gestão Empresarial em Turismo, e Reinaldo, 47 anos, é também graduado em Administração de Empresas. Antes de abrir o próprio empreendimento, trabalhou por muitos anos em um banco estadual, em diferentes agências do Paraná: Cornélio Procópio, Andirá, Joaquim Távora e Cambará. Atualmente, a matriz da agência de turismo está localizada na cidade de Cambará, e sua filial na cidade de Cornélio Procópio.

Os quadros 6 e 7 apresentam resumo dos tipos de redes que foram criados pela empresa e dos recursos obtidos nas fases de criação e desenvolvimento do negócio.

Quadro 6

Resumo dos tipos de redes nas fases de criação e desenvolvimento

\begin{tabular}{|l|l|l|}
\hline \multirow{2}{*}{ Criação } & Formais & Operadoras e agências de turismo. \\
\cline { 2 - 3 } & Informais & Amigos, vizinho, ex-colegas de trabalho e clientes. \\
\hline $\begin{array}{l}\text { Desenvolvi- } \\
\text { mento }\end{array}$ & Formais & Operadoras e agências de turismo. \\
\cline { 2 - 3 } & Informais & Amigos, colegas de trabalho e clientes. \\
\hline
\end{tabular}

Fonte: Desenvolvido pelas autoras com base na pesquisa de campo.

Quadro 7

Resumo dos recursos obtidos nas fases de criação e desenvolvimento do negócio

\begin{tabular}{|c|c|c|}
\hline Criação & Sociais & $\begin{array}{l}\text { - } \begin{array}{l}\text { Identificação de ocasiões de negócios, nos contatos com os clientes. } \\
\text { - }\end{array} \text { Contratação de funcionário, pela indicação do sócio da Van. } \\
\text { - } \quad \text { Obtenção de apoio moral e motivacional, dicas e ideias da filha de um } \\
\text { amigo, Ana, turismóloga em Curitiba. } \\
\text { - } \quad \text { Acesso a serviço de consultoria, sem custos, sobre pesquisa de mercado, } \\
\text { com consultores do Sebrae durante a realização do curso EMPRETEC. } \\
\text { - } \quad \text { Uma das primeiras viagens realizadas pela agência foi decorrente do fato } \\
\text { de o Reinaldo ser membro de um Clube de Serviços. } \\
\text { - } \quad \text { Negociação com o proprietário de imóvel a ser utilizado como sede da } \\
\text { empresa facilitada pela posição que ocupava no banco. } \\
\text { - Contratação de funcionária para agência facilitada graças à mobilização de } \\
\text { contatos com uma ex-colega de trabalho. } \\
\text { - Facilidade nas negociações com uma pousada bastante solicitada pelos } \\
\text { clientes, em decorrência da mobilização de contatos com a funcionária de } \\
\text { uma operadora turística. } \\
\text { - Informações e dicas valiosas, bem como orientações sobre como conduzir } \\
\text { o negócio "turismo", recebidas de uma funcionária da CVC. } \\
\text { - Indicações de fornecedores importantes para o negócio. } \\
\text { - Aumento do conhecimento técnico e teórico sobre o assunto através da } \\
\text { realização de cursos e treinamentos. }\end{array}$ \\
\hline
\end{tabular}




\begin{tabular}{|c|c|c|}
\hline & & 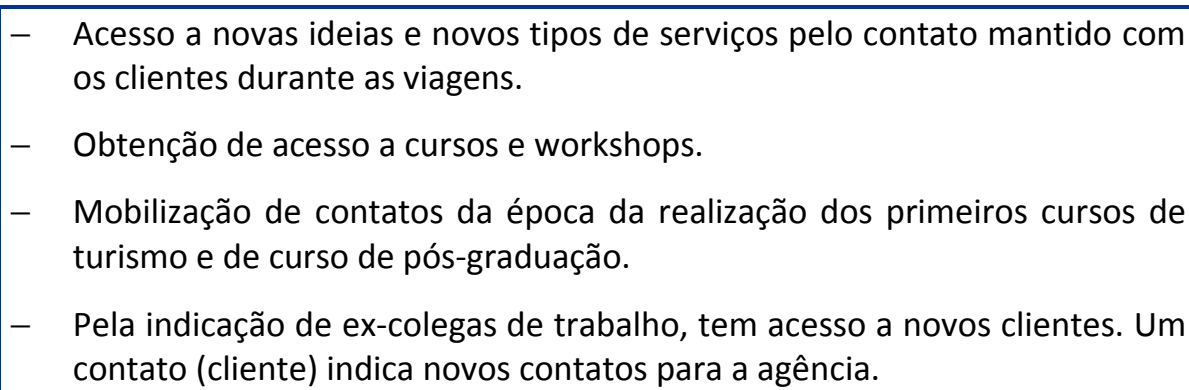 \\
\hline & Financeiros & $\begin{array}{l}\text { - Captação de recurso com um amigo que se tornou sócio na aquisição de } \\
\text { um veículo de transporte. } \\
\text { - Captação de recurso com o banco em que trabalhou para a compra de } \\
\text { outro veículo da frota. }\end{array}$ \\
\hline & Físicos & $\begin{array}{l}\text { - Por ser funcionário do banco, tinha acesso a um terreno ao lado do banco, } \\
\text { que era utilizado como estacionamento para os veículos da sua frota, sem } \\
\text { custo. } \\
\text { - Pelo fato de ser amigo do dono de um posto onde abastecia, passou a } \\
\text { guardar a frota de veículos no pátio desse estabelecimento. } \\
\text { - Instalação em local estratégico na cidade pela indicação de um contato. }\end{array}$ \\
\hline \multirow[t]{2}{*}{$\begin{array}{l}\text { Desenvol- } \\
\text { vimento }\end{array}$} & Sociais & 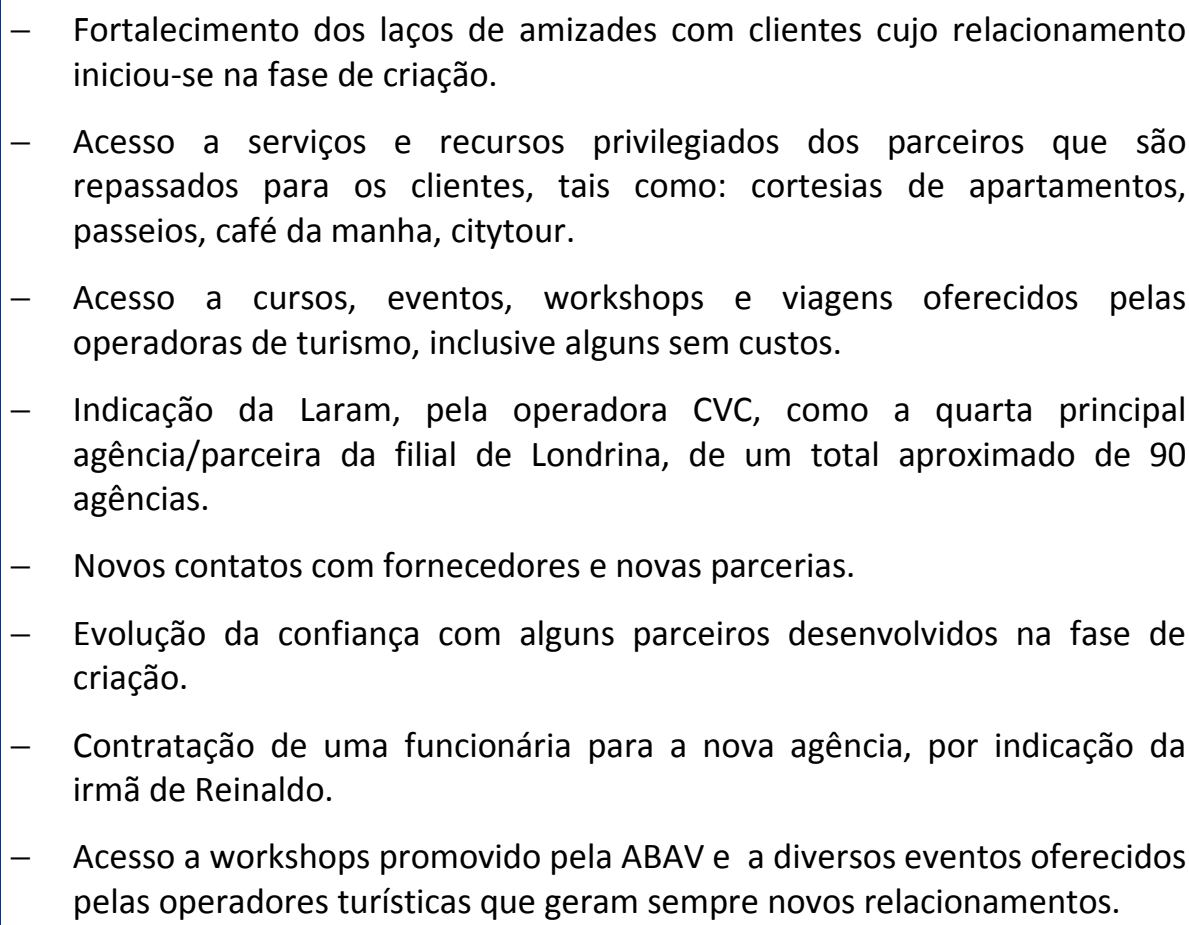 \\
\hline & Físicos & $\begin{array}{l}\text { - Acesso ao dono de um imóvel de localização estratégica para a instalação } \\
\text { da agência em Cornélio Procópio. }\end{array}$ \\
\hline
\end{tabular}

Fonte: Desenvolvido pelas autoras com base na pesquisa de campo. 
Procedeu-se a seguir análise comparativa dos casos, baseada nas categorias analíticas do estudo, destacandose as diferenças e similitudes entre os casos analisados, assim como o relacionamento com a base teórica.

\section{Análise Comparativa dos Casos}

Após a descrição dos três casos, procedeu-se a análise comparativa baseada nas categorias analíticas do estudo: tipos de redes desenvolvidos e os recursos que influenciaram na formação do capital social e que foram obtidos nas fases de criação e desenvolvimento do negócio. Procurou-se destacar as diferenças e similitudes entre os casos analisados, bem como relacionar esses resultados com a base teórica já apresentada.

\section{Tipos de redes nas fases de criação e desenvolvimento do novo negócio}

Ao defender a tese de que, para alguém se tornar um empreendedor de sucesso, é preciso fazer uso do networking, Laird (2006) destaca que as relações sociais que são estabelecidas e desenvolvidas são cruciais para o sucesso do negócio.

Conforme destaca Birley, Cromie e Myers (1990), as redes baseiam-se em relacionamentos sociais, família, amigos, vizinhos, assim como em clientes, vendedores e credores. De acordo com Birley (1985), os empreendedores, na fase de criação de um negócio, confiam decididamente na sua rede informal dos amigos, nos membros da família e nos contatos sociais, objetivando coletar dados relevantes para seu negócio.

Autores, como Aldrich e Dubini, (1991), destacam que os indivíduos se voltam, no início do desenvolvimento do negócio, para a família, apoiando-se em contatos de negócios anteriores, em amigos e ex-empregadores, em busca de recursos físicos, de capital e de suporte emocional, necessários para transformar sua ideia em negócio. Observou-se que, nos casos analisados, apesar de as redes informais terem sido utilizadas mais intensamente pelos três empreendedores, o apoio da família como suporte emocional não foi identificado. Por exemplo, na empresa ForLogic, observou-se que os pais dos sócios nunca aprovaram a ideia de eles manterem um negócio próprio, ao passo que suas companheiras sempre os apoiaram.

A relevância de contatos fora da família pode ser observada ainda no caso da empreendedora da Escola Florence, quando relata que a amizade desenvolvida com um dos médicos, com quem trabalhava, fortaleceu e influenciou seu aprendizado e a levou a identificar uma nova oportunidade de negócio. No caso da ForLogic, na fase de criação do negócio, Jeison e Diogo se associaram com dois amigos, alunos da UTFPR, o que propiciou a criação da empresa de software em sociedade. Na fase de desenvolvimento, observam-se os contatos mantidos com as outras empresas e colegas de profissão da APL Tecnológica.

Já no caso da Laram Turismo, destacam-se os contatos estabelecidos pelos empreendedores com os excolegas de banco e com as funcionárias de operadoras de viagens, que lhes proporcionaram informações essenciais facilitadoras da compreensão do setor e do negócio. Alguns desses contatos se tornaram bastante frequentes gerando fortes ligações.

Para Borges (2005), os laços fortes têm três características: interação frequente, história de relacionamento e relação de intimidade. Eles desempenham também um papel de suporte (emocional, moral etc.) para empreendedor em suas decisões.

Quanto às redes formais, destacaram-se os relacionamentos mantidos com os órgãos governamentais (prefeitura, órgãos ligados à saúde e educação do município e estado), desenvolvidos pelos empreendedores da Escola Florence e da Empresa ForLogic. 
Um importante exemplo é o do vínculo empregatício mantido pela empreendedora da Escola Florence com as prefeituras da região, com a Santa Casa e com hospitais atendidos por essa instituição, na fase de criação do novo negócio. Posteriormente, ao passar para a fase de desenvolvimento, o fato de a empreendedora acumular a função de secretária da saúde do município facilitou a ampliação da sua rede de relacionamentos formais e informais.

A ForLogic, por sua vez, foi pré-incubada pelo Hotel Tecnológico da UTFPR, e o fato desta universidade estar envolvida nesse processo acabou facilitando o acesso a contatos e a manutenção desses relacionamentos. No caso da Laram Turismo, destacam-se alguns contatos formais, com operadoras de turismo e com agências.

De forma geral, percebe-se nos casos estudados, que as relações formais se desenvolveram de forma mais intensa na ForLogic e na Escola Florence. No caso da ForLogic, sua criação está vinculada a um órgão governamental e foi a primeira empresa incubada.

\section{Recursos obtidos nas fases de criação e desenvolvimento do novo negócio}

É importante ressaltar que nos três casos analisados, conforme sugerem os autores Aldrich e Zimmer (1986), observou-se a dependência dos empreendedores da sua rede de relacionamentos, seja para acessar, seja para obter diferentes recursos (sociais, físicos e financeiros).

\section{Recursos Sociais}

Alguns autores, como Johannisson (1998); Aldrich e Zimmer (1986); Aldrich e Dubini (1991), bem como Barnir e Smith (2002), destacam que os contatos têm como objetivo não só obter os recursos econômicos para iniciar o negócio, mas também buscar apoio para a ideia do negócio, conselhos, e informações, e suporte social, e apoio emocional e moral para a constituição da empresa.

Pode-se constatar, no caso da empresa ForLogic de software, que a ideia inicial do negócio a ser criado pelos sócios Jeison e Diogo era um tanto vaga, e quando conheceram os outros dois colegas da graduação, durante uma viagem oferecida pelo Hotel Tecnológico, trocaram ideias, conhecimento e experiências desencadeando uma sociedade e o direcionamento do tipo de negócio a ser criado.

Autores como Larson e Starr (1993), Johannisson (1998, 2000), defendem que os indivíduos se voltam, inicialmente, para sua rede de relacionamentos pessoais (ex-professores, ex-colegas de trabalho ou amigos), em busca dos recursos necessários para a criação e posterior desenvolvimento do negócio.

É importante ressaltar que, na fase de criação, teve destaque o papel exercido pelo gerente da incubadora, pela ouvidora da UTFPR e pelo contador, os quais sempre ofereceram aos empreendedores outros recursos, tais como conselhos, apoio moral, motivacional e emocional necessários ao desenvolvimento do negócio. Esse apoio também se estendeu para a fase de desenvolvimento do negócio, quando novamente esses contatos se fizeram presentes. O coordenador hoje é considerado como amigo e conselheiro, que em todos os momentos de dificuldades ou desânimo apoiou a empresa; assim também como o contador e a ouvidora são destacados como pessoas-chave para o sucesso da empresa.

Considerando a constatação feita por Birley (1985) sobre a forma como o empreendedor é guiado em suas escolhas, a autora cita dois fatores: o emprego precedente, que fornece um modelo inicial dos elementos de uma empresa, e o conselho e auxílio recebidos. Vale (2006) afirma que a experiência passada do atual empresário, como empregado em outra empresa, pode transformar-se em um grande ativo. 
No caso da Escola Florence e Laram Turismo, conforme salientado pelos empreendedores, a ideia de criação do negócio partiu deles e não tinham a intenção de discutir com mais ninguém esta decisão. No caso da empreendedora da Escola Florence, a ideia do negócio veio da sua experiência anterior. Por sua vez, os empreendedores da Laram Turismo relatam que perceberam a oportunidade de negócio (vírgula) e por ocasião de uma viagem (vírgula) foram amadurecendo aos poucos a ideia de criação do negócio.

Alguns autores como Granovetter (1985); Larson e Starr (1993) mencionam que, com o desenvolvimento do negócio, os relacionamentos de trocas podem evoluir com o tempo, e de simples trocas econômicas podem evoluir para um relacionamento baseado em confiança, reciprocidade e adaptação Há criação de comprometimento e confiança.

Vasconcelos (2004) diz que, com o desenvolvimento do negócio, os relacionamentos podem evoluir quando os atores mantêm relações e realizam negócios por longo tempo, adaptando-se mutuamente quanto à condução dos negócios e trocando, frequentemente, informações sobre o mercado.

Nos casos analisados, é possível observar não somente a influência que os contatos tiveram no negócio, mas também a expansão de alguns desses relacionamentos. No caso da escola Florence, destaca-se o relacionamento mantido com o provedor da Santa Casa, que levou o projeto do negócio para aprovação da diretoria, que abriu as portas da Santa Casa como campo de estágio para a escola, que apresentou o projeto para o prefeito da cidade, que se tornou amigo e sócio de um novo negócio da empreendedora.

Observa-se, na empresa ForLogic, o relacionamento com o coordenador do projeto de incubadora, que cedeu um espaço para os empreendedores no habitat tecnológico, mesmo depois de o projeto deles não ter sido escolhido pela banca de seleção. Outro relacionamento que se prolongou foi com o contador, que a princípio foi contratado para a formalização da situação da empresa, e posteriormente passou a assessorar em diferentes assuntos, até sem ter remuneração.

Na empresa Laram Turismo, destacou-se, na fase de criação do negócio, o contato frequente desenvolvido com a funcionária da operadora $\mathrm{CVC}$, que ensinou aos empreendedores muitas das peculiaridades do negócio.

Alguns autores, como Birley, Cromie e Myers (1990); Shaw e Conway (2000) destacam que as redes pessoais criadas pelos empreendedores cumprem vários papéis incluindo-se a provisão de suporte social, estendendo para competências estratégicas para identificar ameaças e oportunidades e completando recursos internos para resolver problemas particulares.

$\mathrm{Na}$ escola Florence, a convivência da Alexsandra com sua equipe de profissionais permitiu detectar a carência de competências, levando-a a visualizar a oportunidade de negócio, no caso a criação de uma escola técnica de Enfermagem. Ainda, graças ao contato mantido com o amigo radiologista, ela começa a capacitarse para a criação de um novo curso nessa área para a escola.

Na ForLogic, quando os empreendedores se filiaram ao APL de TI de Londrina, na fase de desenvolvimento, as interações desenvolvidas com os outros membros proporcionaram experiências, trocas de informações, aprendizado a respeito das tendências de inovações tecnológicas e acesso a novos negócios.

Com relação à empresa Laram Turismo, a oportunidade de negócio foi percebida pela identificação de suas necessidades, ocorrida na primeira viagem, e depois, através das pessoas com as quais os empreendedores mantinham contatos.

Ao iniciarem as operações, as empresas necessitam contatar clientes e fornecedores para a aquisição de materiais e venda dos produtos. Como são empresas novas, são desconhecidas dos mercados fornecedores e compradores. Dessa forma, o acesso a estes mercados é fundamental, sendo a indicação de pessoas conhecidas uma importante fonte de informações (VASCONCELOS, 2004). 
Aldrich, Elam e Reese (1996) destacam que as redes sociais podem ajudar a obter clientes, tecnologia, fornecedores, recursos físicos, recursos financeiros, suporte motivacional e pessoal. Por sua vez, Birley, (1985); Lechner e Dowling, (2003) consideram que as redes podem fornecer informações sobre clientes, concorrentes e fornecedores.

No caso da ForLogic, a indicação de clientes foi feita pelo coordenador do projeto do Hotel Tecnológico e pela gerente de relações da incubadora. Ainda por indicação de um professor da UTFPR os empreendedores, puderam desenvolver, como cliente, a Cooperativa Sicoob com a qual mantêm negócios até o momento. Especificamente na fase de desenvolvimento, outra indicação que se destacou foi a realizada pela sogra, referente à prestação de serviços para uma escola.

No caso da empresa Laram Turismo, logo na fase da sua criação, graças à indicação feita pelo Lions Club, ela pôde desenvolver um novo pacote para uma viagem, em grupo, organizada para diferentes clientes que depois se mantiveram fiéis à agência,

No entanto, na escola Florence a conquista de novos clientes não se deu de forma tão direta como nas demais empresas, pois em nenhum momento é lembrado pela empreendedora um contato de destaque que tenha feito alguma indicação.

Para Hite (2001), os intermediários exercem um papel de destaque nas duas fases de negócios e permitem a pessoas sem vínculos de relacionamento desenvolverem relações de confiança e trocas econômicas. Para a autora, os laços propiciados por intermediários estreitaram-se mais rapidamente, gerando confiança, comprometimento, afeição e trocas comerciais. Nos casos estudados, evidenciam-se as indicações de pessoas que foram depois contratadas e passaram a desempenhar papel importante para formar o quadro pessoal dos empreendimentos.

Ressalta-se a contratação dos profissionais que formariam o quadro de professores da escola Florence. A empreendedora fez contato com alguns amigos de profissão e os convidou a fazer parte da sua equipe de professores, um dos quais foi seu amigo de faculdade.

Na ForLogic, com referência às indicações para contratação de pessoas, a indicação de alunos feita por professores para realização de estágio na empresa, bem como as contratações de funcionários por indicação dos sócios, foram feitas graças aos contatos mantidos com os candidatos, amigos de faculdade. No caso da Laram Turismo, a indicação foi feita pelo sócio e por parentes, para a contratação de funcionário, motoristas e secretária, nas duas fases do negócio.

Borges (2005), em trabalho realizado com um grupo de pequenas e médias empresas, constatou que as redes de relacionamentos mantidas pelos empreendedores proporcionaram diferentes tipos de informação, que facilitaram a aprendizagem, adaptações ao ambiente e inovações.

Com relação à participação em treinamentos, feiras, workshops, os empreendedores de dois negócios, ForLogic e Laram Turismo, apontaram, com destaque, os recursos acessados nas duas fases do negócio. No caso da ForLogic, esses foram proporcionados nas duas fases do negócio pelo coordenador da UTFPR e oferecidos, na maioria das vezes, sem custo, ou mediante algum pagamento facilitado. Os empreendedores das duas empresas relataram que, durante muitos dos cursos, foi possível construir uma rede de relacionamentos com os demais participantes, o que rendeu muitas informações úteis ao desenvolvimento do negócio.

Aldrich, Rosen e Woodward (1987), mencionaram que os indivíduos obtêm de seus relacionamentos, não necessariamente recursos, mas sim assistência, de caráter legal, contábil e financeiro, e contato com investidores e outras pessoas que têm condições e se dispõem a colaborar para a implantação do negócio. 
No caso da escola Florence, quando a empreendedora visitou outra escola técnica modelo, ou quando manteve contato com ex-professoras, obteve ideias que viabilizaram a criação da escola e ajudaram no sucesso do negócio. Na fase de desenvolvimento, graças às sugestões de alguns amigos médicos, resolveu criar uma Faculdade de Enfermagem. A empreendedora Alexsandra destaca, ainda, influência que o gerente de uma agência bancária teve no sucesso de seu negócio, a ligação estreita que teve com ele e sua atuação como uma espécie de consultor.

Em relação à empresa de software, é importante ressaltar também o papel do contador, que, inicialmente contratado para a prestação de serviços de contabilidade, passou a atuar como um consultor de negócios, oferecendo apoio, conselho e suporte em diferentes assuntos da empresa.

Com referência à empresa Laram, pode-se mencionar o relacionamento mantido com a funcionária da operadora CVC que deu suporte em diferentes atividades relacionadas às contratações e orientou também quanto aos valores e tributos referentes ao fechamento dos pacotes de viagem, passo importante na evolução do negócio.

Segundo Johannisson (1990, p. 3), "alguns dos recursos acessados podem fornecer soluções diretas aos problemas operacionais enquanto outros podem aumentar a legitimidade da empresa no mercado e fornecer indiretamente o acesso aos recursos necessários para a perseguição dos objetivos econômicos". Gnyawali e Madhavan (2001, apud Vasconcelos, 2004), ressaltam que alguns relacionamentos do empreendedor podem oferecer ao novo negócio recursos intangíveis como legitimidade e status.

O trabalho desenvolvido pela empreendedora Alexsandra fez com que a Santa Casa abrisse suas portas para a realização dos estágios da escola e a prefeitura passasse a apoiá-la, oferecendo outros recursos. Destaca-se aqui a confiança que o provedor da Santa Casa depositou no empreendimento e o reconhecimento do trabalho da empreendedora e da seriedade da sua escola.

Para Menezes (2007), o reconhecimento tem um componente emocional de peso e estimula o empreendedor a continuar na missão com motivação. O reconhecimento posiciona o nome do empreendedor, dando-lhe status e prestígio. Nhoria (1992) menciona que aquisição desses recursos sociais é sugerida como sendo importante para empresas iniciantes, pois elas contam com pouca legitimação no início das operações e necessitam obter reputação e credibilidade para a sua ampliação.

Um dos resultados diz respeito aos recursos sociais status, relação de confiança e legitimação. No caso da empresa ForLogic, embora o projeto desenvolvido para o primeiro cliente não tenha proporcionado retorno financeiro significativo, ele proporcionou o crescimento profissional da equipe e aumentou sua reputação como desenvolvedora de software. Cabe salientar, ainda, que o software desenvolvido foi indicado como projeto a ser submetido ao CNPq, o que veio a expandir a possibilidade de novos negócios.

$\mathrm{Na}$ empresa Laram, esse recurso destacou-se também na fase de desenvolvimento, quando a empresa recebeu uma classificação de destaque junto à operadora $\mathrm{CVC}$, o que fez aumentar a reputação da empresa perante os clientes da cidade e região. Segundo Paiva Junior (2005), a confiança que os membros de uma rede depositam no empreendedor é útil para angariar o comprometimento social e econômico.

\section{Recursos Físicos}

Os empreendedores conseguiram os locais para a instalação de seus negócios através de seus contatos pessoais. Na fase inicial, a empresa ForLogic consegue instalar-se no próprio Hotel Tecnológico por um tempo e depois tem acesso a uma sala no centro da cidade. Já na fase de desenvolvimento, novamente mantém-se esse recurso, quando são convidados a utilizar o espaço da Incubadora. 
No caso da Laram Turismo, a localização de um bom ponto comercial, na fase de criação, foi importante, mas na fase de desenvolvimento, o novo ponto negociado em Cornélio Procópio, localizado em local mais estratégico, foi fundamental para a consolidação do negócio. Por sua vez, a Escola Florence se estabelece, na fase inicial, em um prédio bem localizado, mas é na fase de desenvolvimento que a empreendedora consegue, graças a seus relacionamentos, um ponto mais estratégico que a motiva, inclusive, a investir no imóvel.

Em relação a alguns outros recursos físicos, como móveis, equipamentos, medicamentos e livros, verificouse que o acesso a eles foram observados de forma mais intensa na empresa escola Florence que os conseguiu de forma mais fácil graças a sua rede de contatos.

\section{Recursos Financeiros}

Os recursos financeiros dizem respeito ao capital próprio, às reservas de lucro da organização e aos capitais de terceiros, tais como crédito de bancos e a fornecedores (VASCONCELOS, 2004). Para Aldrich, Elam e Reese (1996), os indivíduos podem obter recursos financeiros de parentes e amigos, ou encontrar pessoas de seu relacionamento que queriam tornar-se sócios.

Na fase de criação, a Escola Florence obteve um empréstimo financeiro da Santa Casa, enquanto a Laram Turismo conseguiu-o de um banco. Na empresa ForLogic, os recursos financeiros foram concedidos pelo $\mathrm{CNPq}$, na forma de bolsas de estudos para a capacitação dos colaboradores, nas duas fases.

As empresas Florence e ForLogic obtiveram outras formas de apoio financeiro, como, por exemplo, a dispensa do pagamento de aluguel por período determinado, a isenção de taxas de impostos municipais e o desconto em aquisições de fornecedores. Na ForLogic, esse apoio financeiro perdura até o momento, representado pela desoneração das despesas de energia elétrica, telefone, e aluguel.

A Laram Turismo quase sempre financiou suas atividades com recursos próprios e obteve outras formas de apoio como a obtenção de facilidades nas negociações de pacotes, e a obtenção de privilégios (cortesias de apartamentos, de diárias, passeios, citytour), advindos de fornecedores.

Assim, pela análise realizada, um ponto em comum constatado nos três casos é o acesso dos empreendedores aos diferentes recursos, sociais, financeiros e físicos, que contribuíram de forma substancial para a formação do capital social. Porém, é procedente mencionar que nos empreendimentos estudados esse acesso foi do mesmo tipo, mas em intensidade diferente em cada negócio estudado. Destacando-se ainda, uma prevalência dos recursos sociais adquiridos com relação aos físicos e financeiros.

\section{Conclusões}

O interesse do estudo da rede de relacionamentos dos empreendedores não é recente; entretanto, o tema referente à adoção do capital social, como resultante das relações sociais entre o empreendedor e as outras pessoas, é inovador nos estudos sobre empreendedorismo no Brasil. Este estudo constitui-se um esforço para compreender, a partir de um estudo de múltiplos casos, como as redes sociais foram utilizadas pelos empreendedores na obtenção de recursos, influindo na construção do capital social, nas fases de criação e de desenvolvimento de novos negócios. Vale lembrar que o capital social neste estudo foi entendido a partir da utilização das redes sociais que contribuem para o alcance dos objetivos dos empreendedores.

Borges (2007) defende que a ideia básica do conceito de capital social reside no fato de que as relações pessoais podem ser uma fonte de recursos e de apoio e, ainda, destaca algumas das principais contribuições do capital social no processo de criação do negócio: informações e conselhos, conhecimento tecnológico, 
formações, ocasiões de negócios, ideias, recrutamento de sócios e de funcionários, recursos financeiros, suporte moral e emocional, credibilidade, identificação de clientes e fornecedores. Assim, é possível dizer, pelas análises realizadas nos três casos apresentados, que os diferentes recursos acessados pelos empreendedores contribuíram, de forma substancial, para a formação do seu capital social.

Observou-se também que os relacionamentos estabelecidos evoluíram e foram se aprofundando à medida que os empreendedores dos casos descritos puderam provar sua confiabilidade. Para Aldrich e Dubini (1991), a confiança é o elemento básico que determina a solidez das ligações da rede e da permanência do laço, reduzindo os riscos das partes envolvidas. Quando acessa um contato da sua rede, o empreendedor realiza uma troca e desta forma, faz uso de seu capital social, provocando um débito, para o qual há uma reciprocidade esperada.

Os resultados da análise dos casos sugerem que, ao manter uma rede de relacionamentos, do tipo formal ou informal, os empreendedores puderam acessar diferentes recursos e informações. Assim, pode-se argumentar que os diferentes recursos acessados pelos empreendedores do estudo contribuíram para a formação do seu capital social.

Não se pretendeu esgotar o assunto, mas, levantar algumas questões sobre as redes sociais na formação do capital social. Foi possível identificar neste estudo que é importante investir na formação de redes sociais, estimulando a interação que gera confiança entre o empreendedor e sua rede de relações. Os órgãos e instituições de apoio as PME's podem promover contatos com outros empresários para formar a rede de relacionamentos do empreendedor e para ajudá-lo no desenvolvimento de suas competências sociais.

\section{Referências}

ADLER, P.S.; KWON, S. W. Social capital: prospects for a new concept. Academy of Management Review, v. 2, n. $1,2002$.

ALDRICH, H.; CARTER, N. M. Social networks. In W. B. Gartner, K. G. Shaver, N. M. Carter \& P. D. Reynolds (Eds.), Handbook of entrepreneurial dynamics : the process of business creation. 2004. Thousand Oaks: Sage Publications. Disponível em http://books.google.com.br/books?id=FaD1I6qHSI8C\&dq=Handbook+of+entrepreneurial+dynamics+:+the+process+of +business+creation\&pg=PP1\&ots=WHXWRj8byr\&source=bn\&sig=wvtldOWgejRSci3NL2GU231Z2M8\&hl=pt-

BR\&sa=X\&oi=book_result\&resnum=4\&ct=result\#PPP1,M1. Acesso em: 20/02/2008.

; DUBINI, P. Personal and Extend Networks Are Central to the Entrepreneurial Process. Journal of Business Venturing, v.6, p. 305-313, 1991.

.; ELAM, A. B. A guide to surfing the social networks, In: Sue Birley and Dan Myzuka, editors, Managing Enterprise. London: Pitman. p. 143-148, 1997.

; ROSEN, B.; WOODWARD, W. A Social Network Perspective on Entrepreneurship: Preliminary Findings. Unpublished paper, Department of Sociology, UNC-Chapel Hill, April 1986.

;______ . . The impact of social Networks on business foundings and profit: A longitudinal study. In J. Churchil (Ed.), Frontiers of Entrepreneurship Research. Wellesley, MA: Babson College, p. 154-168, 1987.

.; REESE, P.R.; DUBINI, P. Woman on the verge of breakthrough: networking among entrepreneurs in the United States and Italy. Entrepreneurship and Regional Development, p. 339-355, 1989. 
. ; ELAM, A. B.; REESE, P.R. Strong Ties, Weak Ties, and Strangers: Do Women Business Owners Differ from Men in Their Use of Networking to Obtain Assistance? In: Sue Birley and Ian MacMillan (Eds.). Entrepreneurship in a Global Context. London: Routledge Ltd., p. 1-25, 1996.

. ; ZIMMER, C. Entrepreneurship through social networks. In D. L. Sexton \& R. W. Smilor (Eds.). The Art and Science of Entrepreneurship, Cambridge: Ballinger, p. 3-23, 1986.

BARNIR, A.; SMITH, K. A. Interfirm alliances in the small business: The role of social networks. Journal of Small Business Management, v. 40, n.3, p. 219-232, 2002.

BIRLEY, S. The role of networks in the entrepreneurial process. Journal of Business Venturing, v.1, n.1, p. 107-117, 1985.

; CROMIE, S. Social networks and entrepreneurial in Northern Ireland. In: Proceedings of Action Conference. Belfast, Ireland, 1988.

.; ___ _ MYERS A. Entrepreneurial Networks: Their Emergence in Ireland and Overseas. International Small Business Journal, v. 9, n. 4, p. 56-74, 1990.

BÖGENHOLD, D. Social Capital as Strategic Element of Venture Creation - Paper for Presentation at the 2nd Annual Conference of the European Academy of Management, Proceedings of 2nd ACEAM. Stockholm, May / Sep./Nov. 2002.

BORGATTI, S. P.; FOSTER, P. C. The network paradigm in organizational research: A review of typology. Journal of Management, v.29, n.6, 991-1013, 2003.

BORGES, C. V. Relacionamentos e competitividade. Revista HSM Management, n. 20, maio/ 2005. Disponível em: http://www.hsm.com.br/canais/newsletters/hmu/hmu20.php. Acesso em: 06/02/2008.

Formation du capital social entrepreneurial. 168 f. Tese (Doutorado em Administração) - Universidade de Montreal, Canadá, 2007.

;; SIMARD, G.; FILION, L. J. Venture Creation Processes in Quebec. Research Findings 2004-2005. Working Paper, 2005-07, HEC Montréal: May, 2005.

BOURDIEU, P. Le capital social: notes provisoires. Actes de la recherche em Sciences Sociales, n.3, v.3, p. 2-3, 1980.

The forms of capital. In: J. G. Richardson (Ed.), Handbook of theory and research for the sociology of education. Westport: Greenwood Press, p. 241-258. 1986.

Les structures sociales de l'économie. [Paris]: Seuil, 2000.

BURT, R.S. Structural Holes: The Social Structure of Competition, Boston: Harvard University Press, 1992.

A note on social capital and network content. Social Networks, v. 19, n. 4, p. 355-373, 1997.

Structural holes versus network closure as social capital. In: LIN, N.; COOK, K. E.; BURT, R. S. (Ed.). Social capital: theory and research. New York: Aldine de Gruyter, 2001.

CASTEllS, M. A Sociedade em Rede - A Era da Informação: economia, sociedade e cultura. Porto Alegre: Paz e Terra, 1999.

COLEMAN, J. S. Social capital in the creation of human capital. The American Journal of Sociology, v. 94, S95S121, 1988.

Foundations of social theory. Cambridge: Harvard University Press, 1990. 
COOPER, A. Entrepreneurship: the past, the present, the future. Keynote address to the 1998. Annual Meeting of the

US Association for Small Business and Entrepreneurship. Clearwater, FL, 1998. Disponível em: http://www.smeal.psu.edu/facrsch/report02.html/?searchterm=Entrepreneurship:\%20the\%20Past, \%20the\%20Present, \% 20the\%20Future. Acesso em: 05/01/2008.

CHU. P. Social network models of overseas Chinese entrepreneurship: The experience in Hong Kong and Canadá. Revue Canadienne des Sciences de l'Administration, Dec. 1996.

DAVIDISSON, P.; HONIG, B. The role of social and human capital among nascent entrepreneurs. Journal of Business Venturing, v. 18, p. 301-331, 2003.

EISENHARDT, K. M. Better stories and better constructs: the case for rigor and comparative logic. Academy of Management Review, v.16, n. 3, 620-627, 1991.

GODOY, A. S. Pesquisa Qualitativa: tipos fundamentais. Revista de Administração de Empresas, São Paulo, v. 35, n. 3, p. 20-29, mai./jun. 1995.

GRANOVETTER, M.S. The Strength of Weak Ties. American Journal of Sociology, v. 78, n. 6, p. 1360-1380, 1973.

Economic action and social structure: A theory of embeddedness. American Journal of Sociology, v. 91, n.3, p. 481- 510, 1985.

GREVE, A.; SALAFF, J.W. Social Networks and Entrepreneurship. Entrepreneurship: Theory \& Practice, v. 28 , n. 1, p. 1-22, 2003.

HANSEN, E. L. Entrepreneurial networks and new organization growth. Entrepreneurship: Theory \& Practice, v. 19, n. 4, p. 7-19, 1995.

HITE, J. Evolutionary processes and paths of embedded network ties in emerging entrepreneurial firms. Academy of Management Proceedings. 2001. Disponível em: http://www.accessmylibrary.com/coms2/summary_028619154103_ITM.br\&library. Acesso em: 05/10/2008.

JOHANNISSON, B. Building an Entrepreneurial Career in a Mixed Economy: Need for Social and Business Ties in Personal Networks. In: Academy of Management Annual Meeting, San Francisco, Academy of Management Proceedings San Francisco: ACM, August, 1990.

Personal networks in emerging knowledge-based firms: spatial and functional patterns. Entrepreneurship and Regional Development, v. 10, n. 4, p.297-312, Oct/Dec, 1998.

Networking and entrepreneurial growth. In: SEXTON, D. e LANDSTRON, H. (Ed.) Handbook of entrepreunership. London: Blackwell. 2000.

.; ALEXANDERSON, O.; NOWICKI, K.; SENNESETH, K., Beyond anarchy and organization: entrepreneurs in contextual networks. Entrepreneurship Regional, v. 6, p. 329-356, 1994.

KNOKE, D.; KUKLINSKI, J. H. Network Analysis. In.: THOMPSON, G.; FRANCES, J.; LEVACIC, R. \& MITCHELL, J. (ed.) Markets, Hierarchies \& Networks: the coordination of social life. Sage Publications; Open University, p. 173-182, 1996.

LAIRD, P. W. Pull: Networking and success since Benjamin Franklin. Cambridge: Cambridge University Press. 2006.

LARSON, A.; STARR, J. A network model of organization formation. A network model of organizational formation. Entrepreneurship: Theory \& Practice, v.17, n.2, p.5-16, 1993.

LECHNER, C.; DOWLING, M. Firm networks and firm development: The role of the relational mix. Journal of Business Venturing, v.21, n. 4, p. 514-540, Jul. 2006. 
LI, Y. H. P. Entrepreneurial Networks: A comparison of western and chinese concept. In: Conference 13th Nordic Conference on Small Business Research. 13. Proceedings of NCSBR, May. 2004.

LIN, N. Building a network theory of social capital. IN: Lin, K. S. Cook \& R. S. Burt (Eds.), Social capital: theory and research, p. 3-29, 2001a. New York: Aldine de Gruyter.

Social Capital. A theory of Social Structure and Action, Cambridge: Cambridge University Press, Mintzberg, Henry \& B. Ahlstrand, 2001b.

LOPES, H. E. G. Theoretical Reflections About the Concept of Social Networks. Revista de Administração Contemporânea, v. 8, n. 1, p. 179-200, Jan/Mar., 2004.

MENEZES, R. MTC, Metodologia para Gestão de Processo de Formação Empreendedora em Universidades. 2007. Disponível em: http://www.robertmenezes.com/ index.php - Acesso em: 06/06/2008.

MIZUMOTO, F.M.; ARTES, R.; LAZZARINI, S.G.;HASHIMOTO, M.;BEDÊ, M.A. O Impacto de Capital Humano, Capital Social e Práticas Gerenciais na Sobrevivência de Empresas Nascentes: Um Estudo com Dados de Pequenas Empresas no Estado de São Paulo. In: ENCONTRO DA ASSOCIAÇÃO NACIONAL DE PÓS- GRADUAÇÃO E PESQUISA EM ADMINISTRAÇÃO, 32, 2008, Rio de Janeiro. Anais.... Rio de Janeiro: ANPAD, 2008. 1 CD-ROM.

NAHAPIET, J.; GHOSHAL, S. Social capital, intellectual capital, and the organizational advantage. Academy of Management Review, v. 23 n. 2, p. 242-266, 1998.

NHORIA, N. Information and search in the creation of new business ventures: the case of the 128 venture group. In: NOHRIA, Nitin e ECCLES, Robert G. (Org.), Networks and organizations: structure, form, and action. Boston: Harvard Business School Press, Cap. 9, p. 240-61, 1992.

OSTGAARD, T. O.; BIRLEY, S. Personal networks and firm competitive strategy: a strategic or coincidental match? Journal of Business Venturing, v. 9, n. 4, p. 281 - 305, 1994. 1996. New venture growth and personal networks. Journal of Business Research, v. 36, n. 1, p. 37-50,

PAIVA JÚNIOR, F. G.; Confiança Nas Interações Sociais do Empreendedor: um Marco de Fortalecimento Dialógico. In: ENCONTRO DA ASSOCIAÇÃO NACIONAL DE PÓS-GRADUAÇÃO E PESQUISA EM ADMINISTRAÇÃO, 29, Brasília, 2005. Anais... Brasília: ANPAD, 2005. 1 CD-ROM.

PORTES, A. Social capital: Its origins and the application in modern sociology. Annual Review of Sociology, v. 24, p. 1-24. 1998: Stable URL:disponível em: http://links.jstor.org/sici?sici=03600572\%281998\%2924\%3C1\%3ASCIOAA\%3E2.0.CO\%3B2-D. Acesso em: 10/03/2008.

PUTNAM, R. Bowling alone: america's declining social capital. Journal of Democracy. n. 6: 1, jan. 1995. . Bowling Alone: The Collapse and Revival of American Community, New York: Simon Schuster, 2000.

RECUERO, Raquel da Cunha. Teoria das Redes e Redes Sociais na Internet. In: XXVII INTERCOM, 27, Porto Alegre, 2004. Anais... Porto Alegre: PUC/RS, 2004.

RENZULLI, L.; ALDRICH, H. E. ; MOODY J. Family Matters: Consequences of Personal Networks for Business Startup and Survival. Social Forces, v.79, n.2, p. 523-546, Dec. 2000.

REYES, JUNIOR. E. Mensuração das Relações Sociais nas Redes Interorganizacionais. In: ENCONTRO DE ESTUDOS ORGANIZACIONAIS DA ANPAD, V, Belo Horizonte, 2008. Anais...Belo Horizonte: ANPAD, 2008.1 CD-ROM.

RIBEIRO, J. C.; SANTOS, F. J. Redes, Investimento Direto Estrangeiro e Desenvolvimento Regional. IN: ENCONTRO NACIONAL ASSOCIAÇÃO PORTUGUESA PARA O DESENVOLVIMENTO REGIONAL. 10, 
Junho, 2003, Anais.. Évora, Portugal. Disponível em: http://www.apdr.pt/boletins/2003/Boletim2-2003.pdf. Acesso em: $30 / 01 / 2008$.

SHAW, E.; CONWAY, S. Networks and the Small Firm, In: Carter and D. Jones-Evans, D., Enterprise and Small Business: Principles, Practice and Policy, London, Financial Times, 2000.

SZERBG, L. The Changing role of entrepreneur and entrepreneurship in network organizations: Knowledge Transfer, Small and Medium-Sized Enterprises, and Regional Development in Hungary, JATEPress Szeged, Small Business Economics p. 81-85 Lengyel, I- ed, Springer, 2003.

TRIVINOS, Augusto N. S. Introdução à pesquisa em ciências sociais: a pesquisa qualitativa em educação. São Paulo: Atlas, 1987.

VALE, G. M. V. Laços como ativos territoriais: análise das aglomerações produtivas na perspectiva do capital social. 394 f. Tese (Doutorado em Administração) - Universidade Federal de Lavras, Lavras, MG, 2006. Disponível em: http://www.scielo.br/scieloOrg/php/reflinks.php. Acesso em: 01/05/2008.

VASCONCELOS, G. M. R. Inserção Social e Recursos: Um Estudo de Caso de Criação e de Desenvolvimento de Novos Negócios. 141 f. Dissertação (Mestrado em Administração) - Pontifícia Universidade Católica de Minas Gerais, Belo Horizonte, MG, 2004. Disponível em: http://www.pucminas.br/biblioteca/. Acesso em: 29/09/2008.

WASSERMAN, S.; FAUST, K. Social Network Analysis: Methods and Applications. Cambridge, UK: Cambridge University Press, 1994.

YIN, Robert K. Estudo de caso: planejamento e métodos. Porto Alegre: Bookman, 2001. 